\title{
A INFLUÊNCIA DOS VALORES RELATIVOS AO TRABALHO NAS DECISÕES DE CARREIRA: UM ESTUDO SOBRE AS PERSPECTIVAS DE DISCENTES DE INSTITUIÇÕES DE ENSINO SUPERIOR
}

\author{
Taís de Andrade \\ tais0206@gmail.com \\ Universidade Federal de Santa Maria - Santa Maria, RS / Brasil \\ Kelmara Mendes Vieira \\ kelmara@terra.com.br \\ Universidade Federal de Santa Maria - Santa Maria, RS / Brasil \\ Vania de Fátima Barros Estivalete \\ vaniafbe@terra.com.br \\ Universidade Federal de Santa Maria - Santa Maria, RS / Brasil \\ Reisoli Bender Filho \\ reisolibender@yahoo.com.br \\ Universidade Federal de Santa Maria - Santa Maria, RS / Brasil
}

http://dx.doi.org/10.1590/1413-2311.0092013.41306

Recebido em 05/04/2013

Aprovado em 21/08/2014

Disponibilizado em 01/12/2014

Avaliado pelo sistema double blind review

Revista Eletrônica de Administração

Editor: Luís Felipe Nascimento

ISSN 1413-2311 (versão on-line)

Editada pela Escola de Administração da Universidade Federal do Rio Grande do Sul.

Periodicidade: Quadrimestral

Sistema requerido: Adobe Acrobat Reader.

\section{RESUMO}

Este estudo tem como objetivo analisar a influência dos Valores Relativos ao Trabalho sobre as Âncoras de Carreira, a partir da perspectiva de discentes de instituições de ensino superior. Para o alcance deste objetivo, partiu-se de duas perspectivas teóricas: a abordagem de Valores do Trabalho proposta por Ros, Schwartz e Surkis (1999) e Porto e Pilati (2010) e as Âncoras de Carreira propostas por Schein (1993). Visando atingir o objetivo do estudo, realizou-se uma pesquisa quantitativa, de caráter descritivo do tipo survey. $\mathrm{O}$ instrumento preenchido por 958 discentes foi baseado na Escala Revisada de Valores Relativos ao Trabalho (EVT-R), de Porto e Pilati (2010), e no Inventário de Âncoras de Carreira, desenvolvido por Schein (1993). Considerando o modelo proposto, optou-se por trabalhar com modelagem de equações estruturais. Os principais resultados encontrados expõem que os valores prioritários entre os discentes investigados, foram Segurança e Realização. Em relação à carreira, houve o predomínio das âncoras Segurança/estabilidade e Desafio Puro. Ainda, a análise do modelo estrutural permitiu identificar que o construto Valores do Trabalho explica $30,5 \%\left(\mathrm{R}^{2}\right)$ da variância do construto Âncoras de Carreira. De maneira geral, tal achado sustenta a

REAd | Porto Alegre - Edição 79 - N 3 - setembro/dezembro 2014 - p. 625-657 
A influência dos Valores Relativos ao Trabalho nas decisões de carreira: um estudo sobre as perspectivas de discentes de instituições de ensino superior

importância das demandas internas, representadas pelos valores que os indivíduos atribuem ao trabalho, sobre as decisões de carreira, pressuposto esse com poucas evidências empíricas, até então.

Palavras-chave: Valores Relativos ao Trabalho; Âncoras de Carreira; discentes de Instituições de Ensino Superior; pesquisa survey; modelagem de equações estruturais.

\title{
THE INFLUENCE OF WORK VALUES IN CAREER DECISIONS: A STUDY ON THE PERSPECTIVE OF UNIVERSITY STUDENTS
}

\begin{abstract}
The aim of this study is to analyze the influence of values related to work over the values related to it over career anchors, from university students' perspective. To achieve the objective, two theoretical perspectives were assumed: the work values' approach proposed by Ros, Schwartz and Surkis (1999) and Porto and Pilati (2010) and the career anchors proposed by Schein (1993). To achieve the article's purpose a quantitative research has been made with a descriptive character like survey. The research's instrument has been answered by 958 students based on Revised Scale of Work Values (EVT-R) from Porto and Pilati (2010) and inventory of Career Anchors, developed by Schein (1993). Considering the model proposed, we have chosen to work with structural equation modeling. The main results found reveal that the priority values among the students in the survey were Safety and Achievement. In relation to career, a predominance of anchors Security/stability and Pure Challenge could be found. The structural model analysis has also identified that the construct of Work Values explains 30,5\% (R2) of the construct of Career Anchors' variance. In general, this result stands the importance of internal demands, represented by values that individuals attribute to work on career decisions, which still has this little empirical evidence.
\end{abstract}

Keywords: work values; career anchors; university students; survey research; structural equation modeling.

\section{LA INFLUENCIA DE LOS VALORES RELATIVOS AL TRABAJO EN LAS DECISIONES DE CARRERA: ESTUDIO SOBRE LAS PERSPECTIVAS DE DISCENTES DE INSTITUCIONES DE ENSEÑANZA SUPERIOR}

\begin{abstract}
RESUMEN
Este estudio tiene el objetivo de analizar la influencia de los Valores Relativos al Trabajo sobre las Áncoras de Carrera, a partir de la perspectiva de discentes de instituciones de enseñanza superior. Para el alcance de este objetivo, se partió de la perspectiva de dos vertientes teóricas: el abordaje de Valores del Trabajo propuesta por Ros, Schwartz y Surkis (1999) y Porto y Pilati (2010), y las de Áncoras de Carrera propuestas por Schein (1993). Anhelando atingir el objetivo de este estudio, se realizó una pesquisa cuantitativa, de carácter descriptivo del tipo survey. El instrumento rellenado por 958 discentes tuvo como base la Escala Revisada de Valores Relativos al Trabajo (EVT-R), de Porto y Pilati (2010) y el Inventario de Áncoras de Carrera, desarrollado por Schein (1993). Considerando el modelo propuesto, se optó por trabajar con modelaje de ecuaciones estructurales. Los principales
\end{abstract}


Taís de Andrade, Kelmara Mendes Vieira, Vania de Fátima Barros Estivalete \& Reisoli Bender Filho

resultados encontrados señalan que los valores prioritarios entre los discentes investigados fueron Seguridad y Realización. En relación a la carrera hubo predominio de las áncoras Seguridad/Estabilidad y Desafío Puro. Todavía, el análisis del modelo estructural permitió identificar que el constructo Valores del Trabajo explica $30,5 \%\left(\mathrm{R}^{2}\right)$ de la valencia del constructo Áncoras de Carrera. De manera general, tal hallazgo sostiene la importancia de las demandas internas, representadas por los valores que los individuos atribuyen al trabajo sobre las decisiones de carrera, presupuesto este con pocas evidencias empíricas hasta el momento.

Palabras clave: Valores Relativos al Trabajo; Áncoras de Carrera; discentes de instituciones de Enseñanza Superior; pesquisa survey; modelaje de ecuaciones estructurales.

\section{INTRODUÇÃO}

O contexto produtivo contemporâneo e as relações laborais vêm passando por transformações significativas nas últimas décadas, afetando as formas de ser dos indivíduos e a sua interação com o trabalho. As mudanças nas formas de trabalho e emprego trazem implicações objetivas e subjetivas, pois a noção de trabalho envolve tanto a dimensão socioeconômica quanto o significado, o sentido e os valores socioculturais dessa experiência (BLANCH, 2003; COUTINHO, 2009). Nesse contexto, estudos sistemáticos sobre o significado que as pessoas atribuem ao trabalho são essenciais para a maior compreensão sobre o papel deste na vida das pessoas, que pode ser central para os indivíduos e também para a sociedade (HARPAZ, 1985).

Com base nessas perspectivas, os Valores Relativos ao Trabalho assumem um papel importante nos estudos organizacionais, pois tais valores orientam o comportamento dos indivíduos no ambiente laboral. Conforme Ros, Schwartz e Surkiss (1999), os Valores Relativos ao Trabalho caracterizam-se como princípios ou crenças sobre comportamentos, guiando as avaliações sobre os resultados e as alternativas no trabalho e influenciando, também, as predisposições dos indivíduos quanto às carreiras profissionais.

Como afirma Soldano (2011), a orientação profissional está cada vez mais guiada pelos valores humanos em relação ao trabalho, pois a carreira é o resultado de um processo de construção pelo qual o indivíduo significa, interpreta e dá coerência a suas experiências e histórias singulares de vida no trabalho (BENDASSOLLI, 2009). Sob o mesmo enfoque, Chang et al., (2011) destacam que as abordagens sobre carreira convergem quanto aos aspectos ligados à interação entre as aspirações pessoais, os valores e a trajetória profissional ao longo da vida dos indivíduos.

Nesse sentido, as escolhas e a trajetória profissional estão associadas às Âncoras de Carreira, descritas por Schein (1993) como o conjunto de autopercepções relativas a talentos, 
A influência dos Valores Relativos ao Trabalho nas decisões de carreira: um estudo sobre as perspectivas de discentes de instituições de ensino superior

habilidades, motivos e necessidades que as pessoas têm com relação ao trabalho que desenvolvem ou que buscam desenvolver. Ressalta-se, ainda, que o conceito de Âncoras de Carreira oferece insights valiosos para a compreensão da diversidade das preferências pessoais e dos padrões contemporâneos de carreira (COETZEE; SCHREUDER, 2011).

Considerando essas abordagens, o foco do presente estudo reside nos fatores intervenientes nas decisões de carreira, não sob a perspectiva de demandas externas, como, por exemplo, questões situacionais do mercado de trabalho, mas a partir de uma abordagem mais profunda, associada às demandas internas, próprias de cada indivíduo, representadas pelos Valores Relativos ao Trabalho. Alguns autores, como Toit e Coetzee (2012) e Wils, Wils e Tremblay (2010), defendem a perspectiva de que os indivíduos escolhem uma carreira devido à importância atribuída a seus valores, destacando a influência desses valores sobre a determinação das Âncoras de Carreira.

Assim, mesmo considerando a relevância da Teoria do Ajustamento ao Trabalho proposta por Dawis e Lofquist (1984), por ser um dos modelos pioneiros em abordar a interação entre o indivíduo e o ambiente laboral, e da Teoria da Autodeterminação (DECI; RYAN, 1995; 2000), que menciona a importância dos valores intrínsecos e extrínsecos relacionados ao trabalho, neste estudo optou-se por abordar os Valores Relativos ao Trabalho a partir da Teoria dos Valores Individuais de Schwartz (1992). Como afirmam Jin e Rounds (2012), a teoria proposta por Schwartz (1992) demonstrou-se apropriada em diferentes culturas e em diversas profissões. Além disso, como afirmam Lyons, Higgins e Duxbury (2010), a natureza transcendental dos valores individuais permite aplicá-los a vários domínios da vida humana, incluindo o contexto do trabalho.

Para tanto, o presente estudo teve como alicerce os modelos propostos por Ros, Schwartz e Surkis (1999) e Porto e Pilati (2010), elaborados com base na teoria pensada por Schwartz (1992). Além disso, considerando a correspondência entre os domínios motivacionais dos valores propostos por Schwartz (1992) e a estrutura das Âncoras de Carreira (WILS; WILS; TREEMBLAY, 2010), esses modelos são mais apropriados para a análise conjunta dos Valores Relativos ao Trabalho e das Âncoras de Carreira propostas por Schein (1993).

Além disso, Leuty e Hansen (2011) destacam que existem poucos estudos sobre a compreensão dos Valores do Trabalho, bem como poucas medidas disponíveis com provas suficientes de validade e confiabilidade, sendo menos expressivas ainda as pesquisas sobre a interação entre os valores e as decisões de carreira (TOIT; COETZEE, 2012). Assim, a investigação dos Valores Relativos ao Trabalho, aliada às Âncoras de Carreira, permite

REAd | Porto Alegre - Edição 79 - N 3 - setembro/dezembro 2014 - p. 625-657 
Taís de Andrade, Kelmara Mendes Vieira, Vania de Fátima Barros Estivalete \& Reisoli Bender Filho

ampliar o entendimento acerca dessa temática, fornecendo novas possibilidades para a melhor compreensão da influência das perspectivas individuais sobre as âncoras de carreira.

A temática em foco assume importância ainda maior no contexto das Instituições de Ensino Superior (IES), tendo em vista os discentes de cursos de graduação. Compreender as perspectivas individuais acerca dos Valores Relativos ao Trabalho e as Âncoras de Carreira desses discentes pode trazer contribuições que vão além do conhecimento do perfil e dos valores desses sujeitos, pois permitem reflexões sobre os motivos que os levam a trabalhar e sua influência nas predisposições de carreira na atualidade. Tal entendimento é complexo, mas poderá também fornecer subsídios para que a educação nas IES, a qual assume funções sociais, culturais e políticas, repense a construção do conhecimento por meio das relações que estabelece com o seu meio, exercitando suas funções de forma aberta e flexível (SANTOS, 2003).

Assim, tendo como objeto de estudo os discentes de cursos de graduação de IES públicas e privadas, localizadas nas regiões central e oeste do Rio Grande do Sul, buscou-se responder o seguinte problema de pesquisa: qual a influência dos Valores Relativos ao Trabalho sobre as Âncoras de Carreira? Desse modo, este estudo tem como objetivos: (i) verificar a hierarquia atribuída pelos discentes aos Valores Relativos ao Trabalho; (ii) identificar as Âncoras de Carreira predominantes entre os entrevistados; e (iii) analisar a influência dos Valores Relativos ao Trabalho sobre as Âncoras de Carreira.

Na seção seguinte, são apresentados os pressupostos teóricos relacionados aos Valores Relativos ao Trabalho e às Âncoras de Carreira. Após, são enfatizados os aspectos metodológicos relativos à coleta e análise dos dados, para, posteriormente (seção três), analisar os resultados encontrados. Por fim, são detalhadas as considerações finais acerca do estudo realizado, bem como apresentadas as limitações e sugestões para pesquisas futuras.

\section{REFERENCIAL TEÓRICO}

\subsection{Valores Relativos ao Trabalho}

Partindo do pressuposto de que o trabalho desempenha um papel fundamental na vida humana, proporcionando oportunidades para satisfazer diferentes necessidades e objetivos, pode-se afirmar que os Valores do Trabalho ocupam uma posição central no padrão geral de valores, mantendo uma relação significativa com os valores pessoais (JIN; ROUNDS, 2012). Ros, Schwartz e Surkiss (1999) explicam que os Valores do Trabalho são influenciados pelos valores individuais gerais, de modo que, quanto mais os valores gerais forem importantes para 
A influência dos Valores Relativos ao Trabalho nas decisões de carreira: um estudo sobre as perspectivas de discentes de instituições de ensino superior

a pessoa, mais ela buscará esses valores no contexto do trabalho. Considerando esses aspectos, Ros e Grad (2005), a partir do modelo proposto por Schwartz (1992), examinaram o significado do valor do trabalho para professores primários e estudantes, constatando correlações significativas entre o trabalho e os tipos motivacionais de valores pessoais.

Assim, os Valores Relativos ao Trabalho caracterizam-se como uma das facetas dos valores individuais (ELIZUR; SAGIE, 1999), sendo definidos como princípios ou crenças sobre comportamentos que guiam as avaliações acerca de resultados e alternativas no contexto laboral (ROS; SCHWARTZ; SURKISS, 1999). Conforme Schwartz e Bilsky (1987), os valores correspondem a representações cognitivas de três necessidades humanas universais: biológicas, sociais de interação e socioinstitucionais de sobrevivência e bem-estar dos grupos. Com base nessas exigências, Schwartz (1992; 2005) desenvolveu uma tipologia contendo dez tipos motivacionais de valores, organizados em uma estrutura bidimensional: abertura à mudança (autodeterminação, estimulação e hedonismo) versus conservação (segurança, conformidade e tradição); autopromoção (poder, realização e hedonismo) versus autotranscendência (universalismo e benevolência).

A partir dos tipos motivacionais de valores propostos por Schwartz, foram identificados, por Ros, Schwartz e Surkiss (1999), quatro tipos de Valores Relativos ao Trabalho: intrínseco - relacionado a metas obtidas pelo conteúdo do trabalho; extrínseco relativo às metas obtidas pelos resultados do trabalho; social - pertinente à busca de relacionamentos interpessoais; e prestígio - compreendido como a busca pelo poder e reconhecimento por meio do trabalho.

No contexto nacional, Porto e Tamayo (2003), também embasados na Teoria de Valores de Schwartz, desenvolveram a Escala de Valores Relativos ao Trabalho (EVT), estabelecendo uma relação entre os valores individuais e os Valores Relativos ao Trabalho. O modelo proposto pelos referidos autores aponta quatro dimensões dos Valores Relativos ao Trabalho: realização no trabalho(busca de prazer, estimulação e independência de pensamento e ação no trabalho por meio da autonomia); relações sociais (busca de relações sociais positivas e de contribuições para a sociedade); prestígio(busca de autoridade, sucesso profissional e poder de influência); e estabilidade(busca de segurança e ordem na vida por meio do trabalho, possibilitando suprir materialmente as necessidades pessoais).

Ao identificar que, em alguns estudos (CAMPOS, 2008; PORTO; TAMAYO, 2007), as dimensões da EVT não apresentaram correlações negativas com os fatores que constituem polos opostos, Porto e Pilati (2010) constataram que os fatores da referida escala não avaliavam todo o conteúdo teórico dos tipos motivacionais da Teoria de Schwartz. Assim, os

REAd | Porto Alegre - Edição 79 - N 3 - setembro/dezembro 2014 - p. 625-657 
Taís de Andrade, Kelmara Mendes Vieira, Vania de Fátima Barros Estivalete \& Reisoli Bender Filho

autores desenvolveram a Escala Revisada de Valores Relativos ao Trabalho (EVT-R), tendo como base a Teoria de Valores Individuais de Schwartz (1999), a Teoria de Valores do Trabalho de Ros, Schwartz e Surkis (1999) e a Escala de Valores do Trabalho. O novo instrumento foi constituído a partir de seis dimensões: Autodeterminação e estimulação, associada ao pensamento e à ação independente, à novidade e ao desafio; Segurança, relacionada à estabilidade e à independência financeira; Conformidade, relativa ao compromisso e à aceitação de normas, de hierarquia e de rotinas de trabalho; Universalismo e benevolência, referente à compreensão, à tolerância e à proteção do bem-estar dos outros; Realização, relacionada ao sucesso pessoal por meio de demonstração de competência de acordo com padrões sociais; e Poder, associada ao status social e prestígio, ao controle ou ao domínio sobre outras pessoas e recursos (PORTO; PILATI, 2010).

Dessa forma, percebe-se uma semelhança entre a Teoria de Valores Individuais proposta por Schwartz (1992), o modelo de Valores Relativos ao Trabalho desenvolvido por Ros, Schwartz e Surkiss (1999), a Escala de Valores Relativos ao Trabalho criada por Porto e Tamayo (2003) e a Escala Revisada de Valores Relativos ao Trabalho (EVT-R) proposta por Porto e Pilati (2010). A correspondência entre as referidas teorias e modelos é ilustrada na Figura 1.

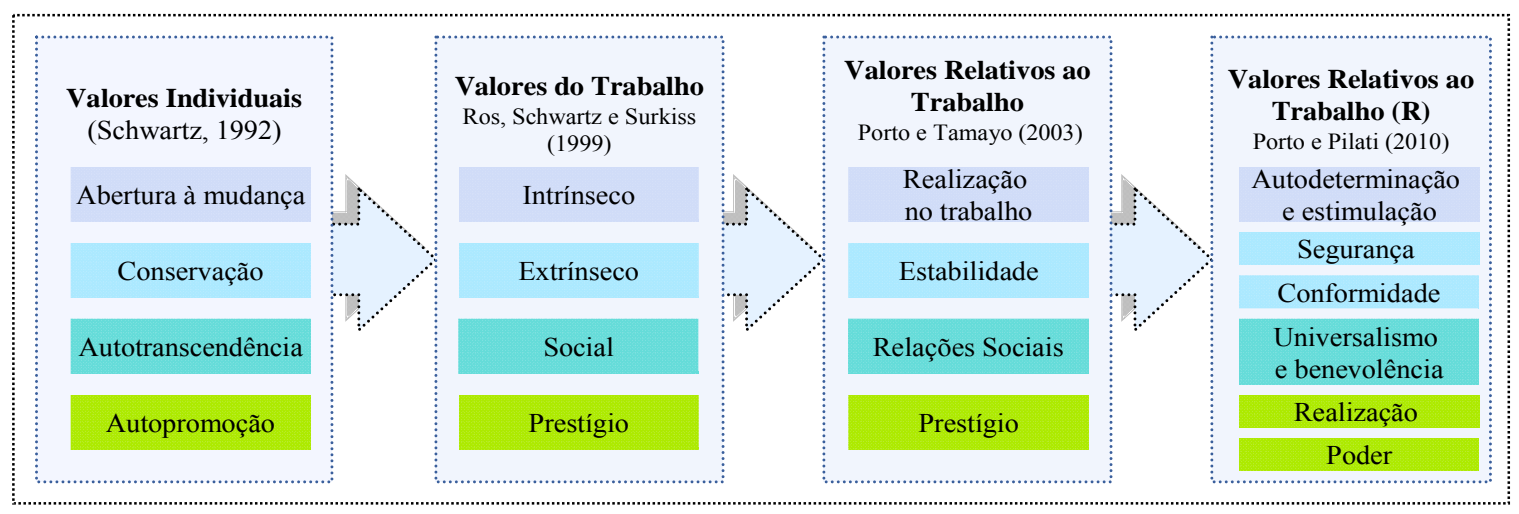

Figura 1 - Interface entre os valores individuais e os Valores Relativos ao Trabalho Fonte: Elaborado a partir de Schwartz (2005); Ros, Schwartz e Surkiss (1999); e Porto e Pilati (2010)

Assim, como afirmam Porto e Tamayo (2003), os valores individuais apresentam uma estrutura universal, a partir da qual estruturas específicas são formadas para contextos específicos, como o trabalho, demonstrando alinhamento entre os estudos internacionais e nacionais (PORTO; TAMAYO, 2003).

A partir dessas perspectivas, percebe-se que os Valores Relativos ao Trabalho guiam o comportamento dos indivíduos no contexto laboral, orientando suas decisões e aspirações profissionais. Conforme afirmam Toit e Coetzee (2012), a atenção dada à compreensão dos REAd | Porto Alegre - Edição 79 - N 3 - setembro/dezembro 2014 - p. 625-657 
A influência dos Valores Relativos ao Trabalho nas decisões de carreira: um estudo sobre as perspectivas de discentes de instituições de ensino superior

valores e das motivações subjacentes às decisões dos indivíduos sobre suas carreiras é um foco em destaque nos estudos sobre o tema e também nas práticas pós-modernas de orientação de carreira. Corroborando essa perspectiva, Wils, Wils e Tremblay (2010) enfatizam também a interação entre os valores e a determinação das Âncoras de Carreira dos indivíduos, confirmando a relevância da análise conjunta desses temas.

\subsection{Carreira: um olhar para as perspectivas individuais acerca das aspirações profissionais}

Os estudos sobre carreira foram abordados a partir de diversas áreas, incluindo a psicologia, sociologia, economia, educação e gestão, conferindo às pesquisas um caráter interdisciplinar (ARTHUR, 2008). No entanto, como afirmam Gunz e Peiperl (2007), somente na década de 1970 esse tema foi estabelecido como um campo dos estudos organizacionais, ganhando destaque nas teorias com ênfase em conteúdo e processo.

Teóricos da área do conteúdo, como Holland (1973) e Jung (1971), focaram suas investigações em características individuais (idade, capacidade, interesses e personalidade), enquanto os teóricos do campo do processo, como Super e Bohn (1980) e Schein (1978), concentraram-se em compreender como as perspectivas individuais de uma pessoa podem influenciar o seu desenvolvimento de carreira ao longo de um período de tempo (LUMLEY, 2009). Considerando as abordagens de processo, Super e Bohn (1980) argumentam que a carreira pode ser compreendida como uma sequência temporal de ocupações, empregos e posições assumidas durante a trajetória profissional, sendo também visualizada como um conjunto de papéis ocupacionais desempenhados por uma pessoa, cuja escolha e cujo sucesso são influenciados por interesses, aptidões, valores e outras necessidades.

Ampliando os estudos de Super e Bohn (1980), Schein (1993) definiu carreira como a maneira que a vida profissional de uma pessoa desenvolve-se ao longo do tempo (carreira externa) e como é vista por ela (carreira interna). A carreira interna está associada às perspectivas dos indivíduos e aos valores pessoais que se estabelecem durante a formação de uma carreira e na relação indivíduo-trabalho, ou seja, às suas Âncoras de Carreira.

Assim, segundo Schein (1993), as Âncoras de Carreira referem-se ao conjunto de autopercepções relativas a talentos, habilidades, motivos, necessidades, atitudes e valores que as pessoas têm com relação ao trabalho que desenvolvem ou que buscam desenvolver. Como afirmam Faro et al. (2010), as âncoras de carreira afetam a forma com que o indivíduo enxerga e percebe seu trabalho e sua carreira. Além disso, o conceito de Âncoras de Carreira oferece insights valiosos para a compreensão da diversidade nas preferências pessoais e dos

REAd | Porto Alegre - Edição 79 - N 3 - setembro/dezembro 2014 - p. 625-657 
Taís de Andrade, Kelmara Mendes Vieira, Vania de Fátima Barros Estivalete \& Reisoli Bender Filho

padrões contemporâneos de carreira (COETZEE; SCHREUDER, 2011). O reconhecimento da âncora de carreira possibilita ao profissional o desenvolvimento de estratégias de carreira que combinem suas habilidades e seus valores com as oportunidades de mercado.

Assim, visando analisar as Âncoras de Carreira, Schein (1996) construiu um inventário que possibilita identificar, entre oito categorias de inclinação profissional, a âncora predominante que revela os valores pessoais dos quais a pessoa não abre mão. O objetivo do Inventário Âncoras de Carreira é incentivar o indivíduo a refletir sobre suas áreas de competência, seus objetivos e seus valores, indicando o seu perfil.

Segundo Chang et al. (2011), a maioria das pessoas formam um forte autoconceito de sua carreira interna, de modo que a âncora predominante é aquela que o profissional não abrirá mão, mesmo em processos difíceis de tomada de decisão, e pode ser identificada a partir de experiências reais de trabalho (SCHEIN, 1993). A classificação e definição das Âncoras de Carreira podem ser visualizadas no Quadro 1.

Quadro 1 - Âncoras de Carreira

\begin{tabular}{|c|c|}
\hline Âncora de Carreira & Definição/características \\
\hline $\begin{array}{l}\text { Autonomia/independência } \\
\text { (AI) }\end{array}$ & $\begin{array}{l}\text { Prioridade à liberdade, autonomia e independência. Caracteriza a valorização } \\
\text { das experiências profissionais de realização do trabalho cujos ritmos, formas e } \\
\text { padrões são autônomos. }\end{array}$ \\
\hline $\begin{array}{l}\text { Segurança/estabilidade } \\
\text { (SE) }\end{array}$ & $\begin{array}{l}\text { Valorização da estabilidade, da previsibilidade dos níveis de desempenho e } \\
\text { tarefas, das recompensas previsíveis e estáveis. }\end{array}$ \\
\hline $\begin{array}{l}\text { Competência técnica- } \\
\text { funcional (TF) }\end{array}$ & $\begin{array}{l}\text { Valorização de experiências profissionais que vislumbrem a capacidade técnica } \\
\text { individual. }\end{array}$ \\
\hline $\begin{array}{l}\text { Competência gerência } \\
\text { geral }(\mathrm{CG})\end{array}$ & $\begin{array}{l}\text { Prioridade à capacidade analítica na solução de problemas e tomada de decisões } \\
\text { em situações de incerteza, ao bom relacionamento interpessoal e intergrupal e } \\
\text { ao equilíbrio emocional. }\end{array}$ \\
\hline $\begin{array}{l}\text { Criatividade } \\
\text { empreendedora }(\mathrm{CE})\end{array}$ & $\begin{array}{l}\text { Criação de novos negócios, produtos ou serviços economicamente rentáveis. } \\
\text { Essa inclinação profissional reúne pessoas dispostas a correr riscos e superar } \\
\text { obstáculos para verem o resultado de seu próprio esforço. }\end{array}$ \\
\hline $\begin{array}{l}\text { Serviço/dedicação a uma } \\
\text { causa (SD) }\end{array}$ & $\begin{array}{l}\text { Prioridade à satisfação em contribuir para a melhoria da sociedade, em tornar o } \\
\text { mundo um lugar melhor para viver, ajudando os outros, solucionando questões } \\
\text { ambientais e sociais. }\end{array}$ \\
\hline Desafio Puro (DP) & $\begin{array}{l}\text { Valorização da superação de obstáculos e solução de problemas aparentemente } \\
\text { insolúveis. }\end{array}$ \\
\hline Estilo de Vida (EV) & $\begin{array}{l}\text { Prioridade ao equilíbrio das esferas pessoais e profissionais. A percepção de } \\
\text { sucesso está relacionada à conquista do equilíbrio, não sendo a carreira o seu } \\
\text { objetivo principal. }\end{array}$ \\
\hline
\end{tabular}

Fonte: elaborado a partir de Schein (1993; 1996); Faro et al.(2010)

REAd | Porto Alegre - Edição 79 - N 3 - setembro/dezembro 2014 - p. 625-657 
A influência dos Valores Relativos ao Trabalho nas decisões de carreira: um estudo sobre as perspectivas de discentes de instituições de ensino superior

O Inventário de Âncoras de Carreira tem sido amplamente utilizado em estudos nacionais e internacionais (FARO et al., 2010; DANZIGER; RACHMAN-MOORE; VALENCY, 2008; COETZEE; SCHREUDER, 2011; WILS; WILS; TREMBLAY, 2010). No entanto, em alguns casos, foram evidenciadas distinções acerca do agrupamento das variáveis e dos fatores do modelo proposto por Schein (1993; 1996), sugerindo a necessidade de novos estudos que visem confirmar a estrutura dos fatores propostos.

Nesse sentido, Wils, Wils e Tremblay (2010), valendo-se do modelo desenvolvido por Schein (1993; 1996), ao constatarem a existência de 10 âncoras, ampliaram as considerações de Schein (1996) sobre a sobreposição das Âncoras de Carreira. Segundo Schein (1996), a classificação das âncoras agrupa necessidades comuns a determinados grupos, podendo haver sobreposição entre elas, o que significa que os indivíduos apresentam necessidades próximas das características de diversas âncoras, podendo ter preferências de ordem primária e secundária (FARO et al., 2010). Para Wils, Wils e Tremblay (2010), essas sobreposições não ocorrem de maneira aleatória, uma vez que existem afinidades e oposições entre as âncoras, as quais podem ser representadas pelo modelo circular de Âncoras de Carreira, ilustrado na Figura 2.

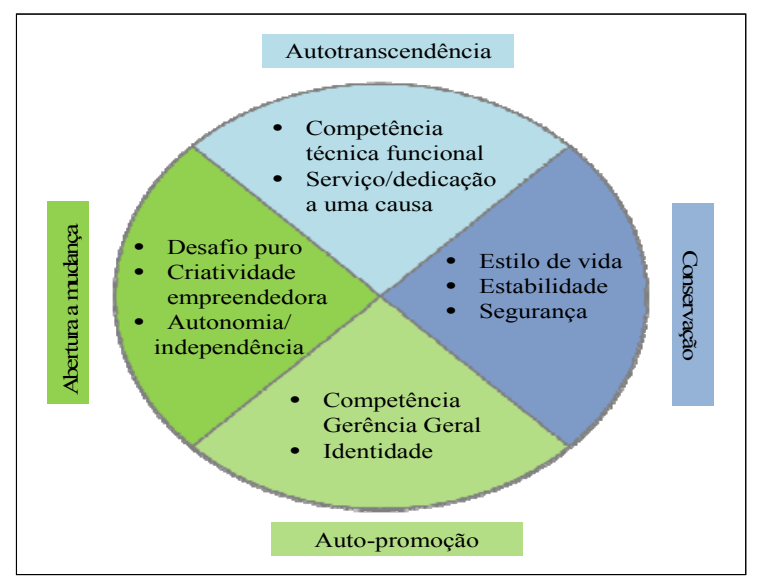

Figura 2 - Modelo Circular de Âncoras de Carreira Fonte: Wils, Wils; Tremblay (2010, p. 243)

O modelo circular considera o fenômeno da dominância de múltiplas carreiras, o qual se fundamenta na correspondência entre os domínios motivacionais dos valores descritos por Schwartz (1992) e as Âncoras de Carreira propostas por Schein $(1993$; 1996). Na visão de Wils, Wils e Tremblay (2010), as âncoras pertencentes à dimensão Autotranscendência (competência técnica e serviço/dedicação a uma causa) opõem-se às âncoras pertencentes à dimensão Autopromoção (competência gerência geral e identidade); e as âncoras pertencentes à dimensão Abertura à mudança (desafio puro, criatividade empreendedora e 
Taís de Andrade, Kelmara Mendes Vieira, Vania de Fátima Barros Estivalete \& Reisoli Bender Filho

autonomia/independência) opõem-se às âncoras da dimensão Conservação (estilo de vida, segurança e estabilidade). No entanto, mesmo sugerindo a existência de dimensões bipolares entre as âncoras e constatando um número diferente de fatores, os referidos autores destacam a pertinência do modelo proposto por Schein (1993; 1996).

Além disso, apesar de Schein (1996) ter enfatizado em sua teoria a perspectiva individual, destacou também a importância de que as organizações viabilizassem carreiras que fossem congruentes com as âncoras de seus colaboradores. Isso se justifica porque a falta de congruência entre a âncora de carreira e a carreira externa pode ocasionar insatisfação, baixo desempenho e rotatividade de pessoal (VAN DAM, 2004). Por outro lado, se os colaboradores combinarem suas atividades profissionais com a sua âncora de carreira, há uma tendência para maior desempenho, satisfação e comprometimento com o trabalho executado (CHANG et al., 2011).

Percebe-se que os debates atuais sobre carreira convergem para algumas questões comuns, especificamente relacionadas à interação entre as aspirações, os valores e a trajetória profissional dos indivíduos (COETZEE; SCHREUDER, 2011; HIRSCHI, 2011; ROWE; BASTOS, 2010). Nesse sentido, o conceito de carreira, diferente de trabalho e profissão, enfatiza a vida dos indivíduos e está intimamente associada aos valores e às preferências pessoais (CHANG et al., 2011), destacando-se a relevância dos Valores Relativos ao Trabalho como antecedentes das decisões sobre carreira.

\section{MÉTODO}

Com a intenção de atingir os objetivos propostos, realizou-se um estudo descritivo com base em uma abordagem quantitativa, o qual tem como propósito obter informações precisas sobre uma população específica, bem como mensurar um evento (HAIR et al., 2009). Como estratégia de pesquisa, realizou-se uma survey, que permite descobrir fatos, determinar atitudes e opiniões e ajudar a entender comportamentos, utilizando-se, para isso, de uma avaliação, análise e descrição de uma população baseada em uma amostra (BAKER, 2001).

Considerando os temas focais deste estudo, a população investigada foi composta por discentes de graduação de IES públicas e privadas das regiões central e oeste do Rio Grande do Sul, pertencentes aos cursos de Administração, Ciências Contábeis, Direito, Educação Física, Serviço Social, Pedagogia e Serviço Social. Foram selecionadas, por conveniência, cinco instituições, das quais três oferecem cursos de graduação na modalidade de ensino presencial e duas possuem exclusivamente cursos de graduação na modalidade a distância.

REAd | Porto Alegre - Edição 79 - N 3 - setembro/dezembro 2014 - p. 625-657 
A influência dos Valores Relativos ao Trabalho nas decisões de carreira: um estudo sobre as perspectivas de discentes de instituições de ensino superior

Aplicaram-se a essas instituições 1000 questionários, obtendo-se um retorno de 974 instrumentos. Destes, foram excluídos 16 questionários, por terem sido parcialmente preenchidos. Assim, a amostra pesquisada perfez um total de 958 discentes, sendo 524 acadêmicos de cursos da modalidade presencial e 434 da modalidade a distância. A coleta de dados foi realizada no período de outubro a novembro de 2012.

Quanto ao instrumento de coleta de dados, foi aplicado um questionário elaborado a partir de dois modelos. O primeiro refere-se à EVT-R, desenvolvida por Porto e Pilati (2010), composto de 38 questões, distribuídas em seis dimensões (Autodeterminação e estimulação; Segurança; Conformidade; Universalismo e benevolência; Realização; e Poder), possuindo uma escala tipo Likert de cinco pontos, variando de "Nada importante" (1) a "Extremamente importante" (5). O segundo instrumento foi o Inventário de Âncoras de Carreira proposto por Schein (1993; 1996), o qual compreende 40 questões distribuídas em oito dimensões (Autonomia/independência; Segurança/Estabilidade; Competência técnica-funcional; Competência gerência geral; Criatividade empreendedora; Serviço/dedicação a uma causa; Desafio puro; e Estilo de vida), com uma escala tipo Likert de seis pontos variando de "Nunca se aplica para mim" (1) a "Sempre se aplica para mim" (6). Dessa forma, o instrumento final foi composto de 78 questões pertencentes às escalas acima mencionadas e 15 questões relativas à identificação do perfil individual e profissional dos respondentes.

\subsection{Modelo de pesquisa}

Os estudos sobre Valores Relativos ao Trabalho evidenciam que estes guiam o comportamento dos indivíduos no contexto laboral, estando associados, inclusive, às decisões e escolhas profissionais (WILS, WILS; TREMBLAY, 2012; TOIT; COETZEE, 2012). Tendo isso em vista, o modelo de pesquisa utilizado verifica a hipótese de que os Valores Relativos ao Trabalho são fatores determinantes das Âncoras de Carreira individuais, como ilustra a Figura 3. Ressalta-se, ainda, que, na representação do modelo de pesquisa, foram omitidas as indicações das variáveis observadas e seus respectivos erros. 
Taís de Andrade, Kelmara Mendes Vieira, Vania de Fátima Barros Estivalete \& Reisoli Bender Filho

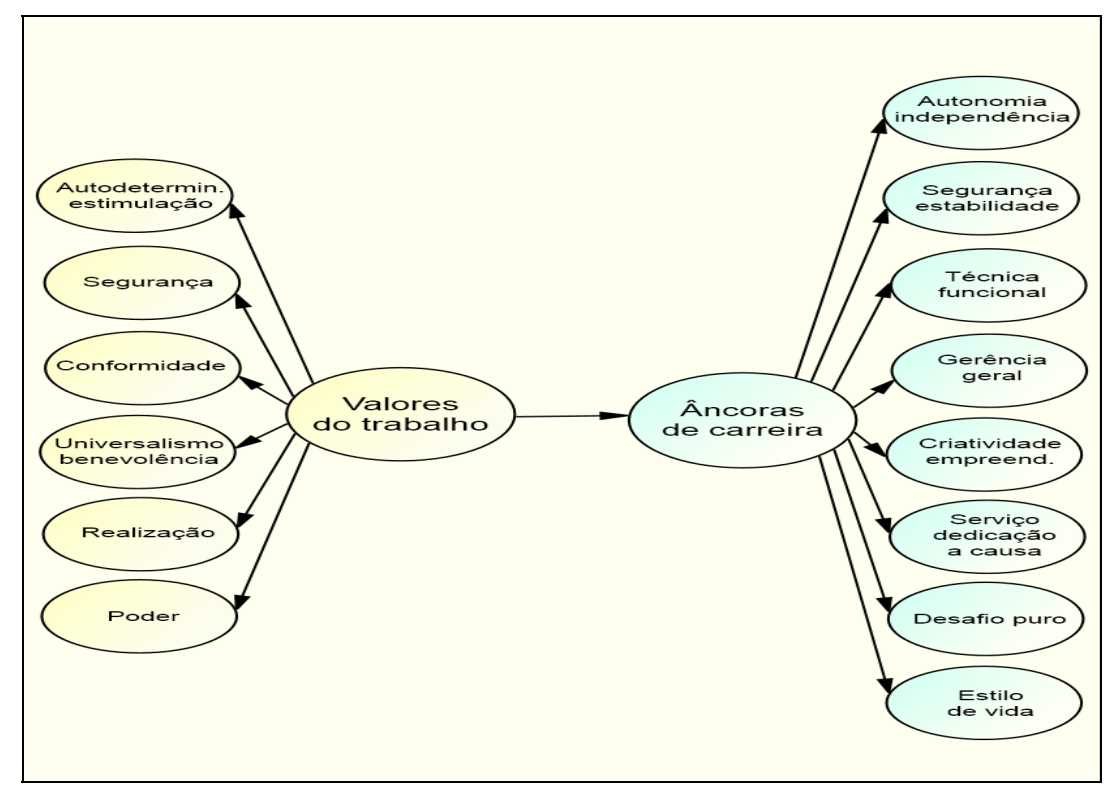

Figura 3 - Modelo de pesquisa Fonte: Elaborado pelos autores

Considerando o modelo proposto, optou-se por trabalhar com a Modelagem de Equações Estruturais (MEE), que, conforme Hair et al. (2009), pode ser usada como um meio de estimar outros modelos multivariados, incluindo regressão, componentes principais e correlação canônica. Essa técnica é entendida por autores como Thompson (2002) e Ullman (2007) como uma combinação de análise fatorial e análise de regressão, que permite aos pesquisadores testar estruturas fatoriais de instrumentos de medida psicométrica, por meio da Análise Fatorial Confirmatória (PILATI; LAROS, 2007). A MEE permite, ainda, a análise de relações explicativas entre múltiplas variáveis simultaneamente, sejam essas latentes ou observadas, apresentando melhores resultados na identificação de relações que as técnicas de primeira geração e proporcionando maior interação entre a teoria e os dados (CHIN, 1998).

Além disso, a complexidade dos fenômenos estudados nas áreas de comportamento organizacional e psicologia sugere que os pesquisadores utilizem técnicas multivariadas condizentes com os fenômenos estudados (PILATI; LAROS, 2007). Nesse contexto, a MEE mostrou-se mais adequada para a análise dos resultados desta pesquisa.

Assim, os resultados foram analisados inicialmente por meio da Análise Fatorial Confirmatória (AFC), que, segundo Kline (1998), consiste em um modelo de mensuração das relações entre os indicadores (variáveis observadas) e os construtos (fatores), visando à avaliação da confiabilidade e da validade dos construtos investigados (HAIR et al., 2009). Conforme Schumacker e Lomax (1996), a confiabilidade indica o grau de consistência interna entre os múltiplos indicadores de um construto, referindo-se à extensão na qual um mesmo instrumento de medida produz resultados coerentes a partir de várias mensurações. A REAd | Porto Alegre - Edição 79 - No 3 - setembro/dezembro 2014 - p. 625-657 
A influência dos Valores Relativos ao Trabalho nas decisões de carreira: um estudo sobre as perspectivas de discentes de instituições de ensino superior

avaliação da confiabilidade do construto foi realizada com base no cálculo da Confiabilidade, da Variância Extraída e do Alfa de Cronbach. De acordo com Hair et al. (2009), o construto é considerado fidedigno se a Confiabilidade atingir valor igual ou superior a 0,7 , a Variância Extraída apresentar valor igual ou superior a 0,5 e o Alfa de Cronbach for superior a 0,7. Já a validade refere-se à extensão na qual as medidas definem um determinado construto (CHURCHILL, 1979).

Posteriormente, foram analisadas as medidas absolutas e as medidas comparativas de ajuste. As medidas absolutas avaliam o grau em que o modelo global prediz a matriz de covariância ou correlação observada (KLINE, 1998). Uma das medidas absolutas de ajuste é o qui-quadrado da razão de verossimilhança $\left(\chi^{2}\right)$, que avalia a significância das diferenças entre a matriz observada e a matriz estimada e que, se for não significativo, indica que os dados se ajustam ao modelo (SCHUMACKER; LOMAX, 1996). Com a intenção de reduzir a sensibilidade desse teste ao tamanho amostral, alguns pesquisadores dividem o valor do quiquadrado pelos graus de liberdade, sendo aceitáveis valores iguais ou inferiores a cinco (PEDHAZUR; SCHMEKLIN, 1991).

Ainda em relação às medidas absolutas, avaliou-se, também, o Root Mean Square Residual (RMSR), o Root Mean Square Error of Aproximation (RMSEA) e o Goodness-of-fit (GFI). O RMSR está associado à distância entre os elementos preditos por meio da estimação dos parâmetros do modelo e os dados observados na matriz de covariâncias, sendo aceitáveis valores inferiores a 0,10 (KLINE, 1998). Já o RMSEA representa a discrepância entre as matrizes observadas e previstas, levando em consideração os graus de liberdade, sendo desejáveis valores inferiores a 0,08 (HAIR et al., 2009). O GFI, por sua vez, baseia-se no cálculo da proporção da variância explicada por meio da estimação, podendo variar de 0 (ajuste ruim) a 1 (ajuste perfeito), sendo aceitáveis valores acima de 0,9 (KLINE, 1998).

Em relação às medidas comparativas de ajuste, utilizadas para comparar o modelo proposto com o modelo nulo, avaliou-se o Comparative Fit Index (CFI), o Normed Fit Index (NFI) e o Tucker-Lewis Index ou Non-Normed Fit Index (NNFI), que devem apresentar valores acima de 0,9 (HAIR et al., 2009). Para a análise dos dados, além da utilização do pacote estatístico SPSS (Statistical Package for the Social Sciences), utilizou-se o software $\mathrm{AMOS}^{\mathrm{TM}}$ para modelagem de equações estruturais. 
Taís de Andrade, Kelmara Mendes Vieira, Vania de Fátima Barros Estivalete \& Reisoli Bender Filho

\section{ANÁLISE E DISCUSSÃO DOS RESULTADOS}

Após a análise descritiva da amostra e dos fatores dos Valores Relativos ao Trabalho e às Âncoras de Carreira, os resultados foram analisados com base em dois enfoques. $\mathrm{O}$ primeiro buscou explorar a Análise Fatorial Confirmatória, apresentando a validação dos construtos de primeira e segunda ordem, e o segundo teve como foco discutir o modelo estrutural integrado.

\subsection{Análise descritiva da amostra}

A amostra investigada foi composta de 958 discentes de graduação de IES, dos quais 337 são discentes de cursos na modalidade presencial de instituições privadas, 187 de cursos na modalidade presencial de instituições públicas e 434 de cursos na modalidade a distância de instituições privadas. Em relação aos entrevistados, constatou-se a existência de $42,1 \%$ de homens e 57,9\% de mulheres, com média de idade de 26,4 anos (desvio padrão de 1,21). Sobre o estado civil dos pesquisados, $67,1 \%$ são solteiros e $20,6 \%$ são casados. Além disso, $26,6 \%$ dos indivíduos afirmaram possuir filhos.

Em relação ao curso de graduação, predominaram os cursos de Administração (50,8\%) e Direito $(13,4 \%)$. O predomínio do curso de Administração está associado ao fato de todas as instituições pesquisadas oferecerem esse curso e de a maioria dos alunos de tais instituições cursarem Administração. Quanto ao semestre, 29,2\% encontram-se no terceiro e quarto semestres e $26,5 \%$ cursam o quinto e sexto semestres. Ainda, a maioria dos entrevistados não possui outro curso de graduação concluído (96,2\%). Esta constatação pode estar associada à variável idade, que, por meio da realização do teste t para amostras independentes, ao nível de $5 \%$ de significância, apresentou diferença significativa entre os indivíduos que possuem curso de graduação concluído e os que não possuem, sendo a idade do primeiro grupo (média de 32,19 anos) superior à idade dos indivíduos do segundo grupo (média de 26,18 anos).

Quanto à experiência profissional, 81,7\% dos entrevistados já exerceram alguma atividade laboral e $71 \%$ estão trabalhando atualmente. Em relação a estes últimos, o tempo de serviço na empresa foi de, em média, quatro anos (desvio padrão de 2,06), com 25,5\% atuando no setor público, 24,3\% no setor de serviços e 23,3\% no setor de comércio. Quanto às funções desempenhadas, $21,5 \%$ dos entrevistados exercem os cargos de auxiliar e assistente administrativo e caixa, $11,8 \%$ ocupam os cargos de gerente ou diretor e 10,7\% exercem atividades profissionais como secretária, balconista e atendente. Tal constatação pode estar associada ao fato de que a maioria dos entrevistados cursa Administração e Direito, os quais

REAd | Porto Alegre - Edição 79 - N 3 - setembro/dezembro 2014 - p. 625-657 
A influência dos Valores Relativos ao Trabalho nas decisões de carreira: um estudo sobre as perspectivas de discentes de instituições de ensino superior

possuem afinidades com os respectivos cargos. Destaca-se, ainda, que 55,7\% dos entrevistados atuam na área em que gostariam de construir carreira, tendo atribuído quanto à sua realização com o trabalho atual, considerando uma escala de 0 a 10, a nota de 7,6.

\subsection{Validação dos construtos de primeira e segunda ordem e análise descritiva}

A fim de identificar a influência dos Valores Relativos ao Trabalho sobre as Âncoras de Carreira, realizaram-se dois procedimentos: o primeiro envolveu a Análise Fatorial Confirmatória (AFC) para a construção do modelo de mensuração e a análise descritiva; e o segundo avaliou as relações de influência entre os fatores, conforme o modelo estrutural.

Para a validação dos construtos, foi realizada a AFC e os relacionamentos entre as variáveis observadas e os seus construtos, sendo estes estimados utilizando o método da máxima verossimilhança. Assim, partiu-se do modelo proposto para a validação da confiabilidade e a obtenção dos índices de ajuste iniciais (GARVER; MENTZER, 1999; HAIR et al., 2009). Como o modelo possui construtos de primeira e segunda ordem, inicialmente realizou-se a avaliação da confiabilidade dos construtos de primeira ordem, por meio do cálculo da confiabilidade e da variância extraída, os quais devem apresentar valores iguais ou superiores a 0,7 e 0,5 , respectivamente.

Como podem ser visualizados na Tabela 2 , os cálculos da confiabilidade e da variância extraída evidenciaram que os valores estavam abaixo do recomendado. Assim, optou-se por retirar as variáveis que apresentaram os coeficientes padronizados mais baixos (inferiores a 0,3), sendo excluídas duas variáveis do construto Autodeterminação e Estimulação, uma variável do construto Segurança/estabilidade, uma variável do construto Técnica Funcional e uma variável do construto Criatividade empreendedora.

Após essas exclusões, a confiabilidade e os índices de ajuste dos modelos apresentaram valores inferiores ao esperado, sendo então excluídas as variáveis com coeficientes inferiores a 0,6. Nesta etapa, foram efetuadas as seguintes exclusões: cinco variáveis do construto Universalismo e Benevolência, quatro variáveis do construto Autodeterminação e Estimulação, três variáveis do construto Conformidade, uma variável dos construtos Segurança, Poder e Realização, duas variáveis dos construtos Técnica funcional e Estilo de vida e uma variável dos construtos Autonomia e independência, Segurança e estabilidade, Gerência geral, Criatividade empreendedora, Serviço e dedicação a uma causa e Desafio puro.

Como os valores dos índices de confiabilidade não foram satisfatórios para todos os construtos, optou-se pelo cálculo do Alfa de Cronbach para verificar a fidedignidade de cada

REAd | Porto Alegre - Edição 79 - N 3 - setembro/dezembro 2014 - p. 625-657 
Taís de Andrade, Kelmara Mendes Vieira, Vania de Fátima Barros Estivalete \& Reisoli Bender Filho

um dos construtos estudados, conforme sugerem Baumgartner e Homburg (1996). Uma vez que os valores do Alfa de Cronbach são considerados satisfatórios se apresentarem valores superiores a 0,7 (Hair et al., 2009), optou-se pela exclusão dos fatores Conformidade (alfa 0,674), Técnica funcional (alfa 0,538) e Estilo de vida (alfa 0,387). Os construtos finais e as respectivas variáveis são apresentados no Apêndice 1.

Ressalta-se que, em estudo realizado por Porto e Pilati (2010), o construto Conformidade (alfa 0,68) também apresentou alfa inferior a 0,7. Quanto aos construtos relacionados às Âncoras de Carreira (Técnica funcional e Estilo de vida), o estudo desenvolvido por Coetzee e Schreuder (2009) também constatou a baixa confiabilidade dos fatores Técnica funcional e Estilo de vida (alfas 0,59 e 0,46, respectivamente). Ressalta-se, ainda, que Danziger et al. (2008) e Wils, Wils e Tremblay (2010) evidenciaram diferenças em relação ao número de fatores proposto por Schein et al. (1993, 1996), sugerindo a necessidade de novas pesquisas para a confirmação da referida estrutura. A Tabela 1 ilustra a variância extraída, a confiabilidade e o Alfa de Cronbach para cada construto de primeira ordem.

Tabela 1 - Resultados da avaliação da confiabilidade dos construtos de $1^{\mathrm{a}}$ ordem

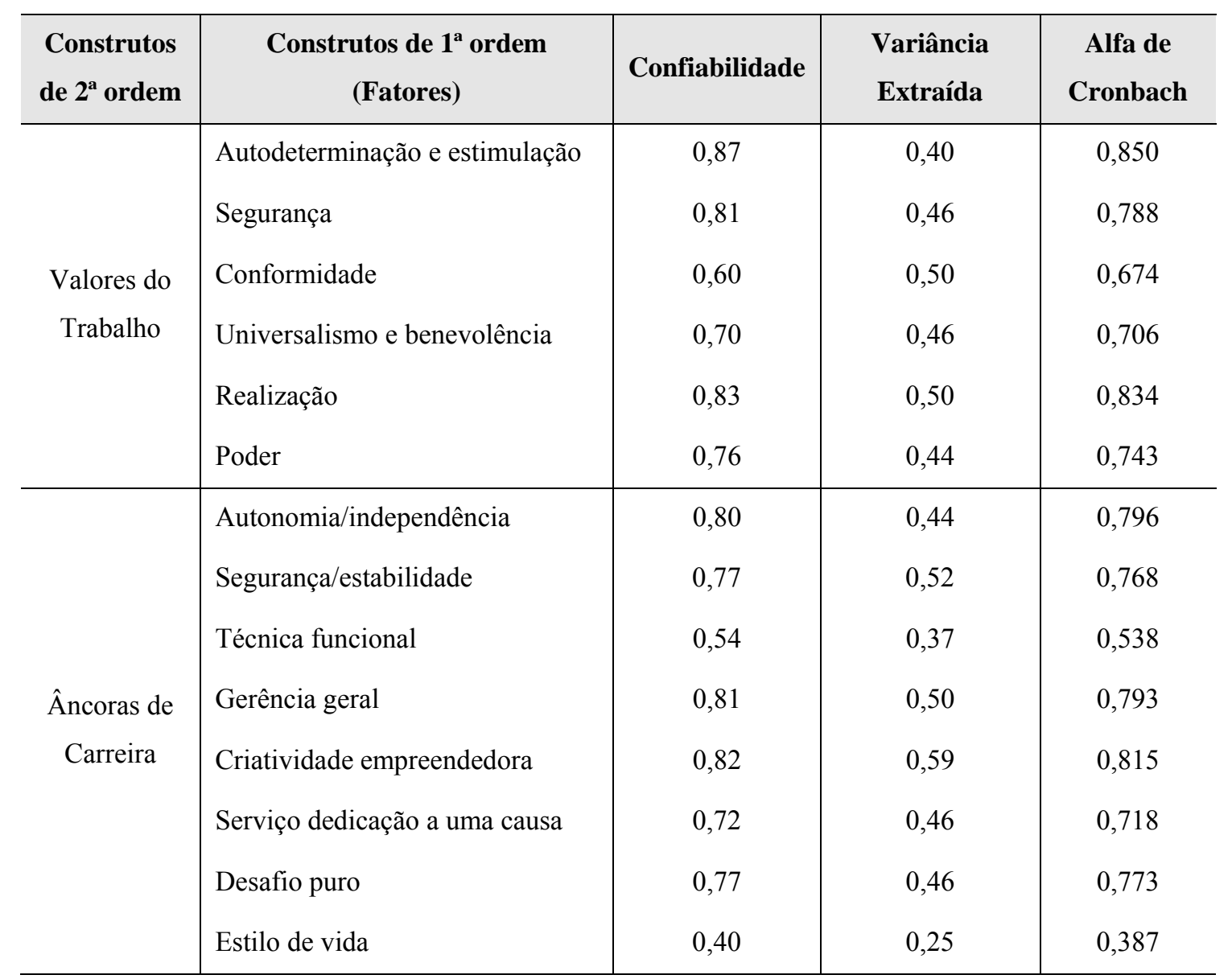

Fonte: elaborado pelos autores com base nos resultados da pesquisa

REAd | Porto Alegre - Edição 79 - N 3 - setembro/dezembro 2014 - p. 625-657 
A influência dos Valores Relativos ao Trabalho nas decisões de carreira: um estudo sobre as perspectivas de discentes de instituições de ensino superior

Em relação aos índices de ajuste, consideraram-se as medidas absolutas e comparativas, tendo como parâmetro o fato de que os valores aceitáveis do $\chi^{2}$ (qui-quadrado) não devem ser significativos $\left(\chi^{2}>0,05\right)$ e, se forem, a divisão do qui-quadrado pelos graus de liberdade deve apresentar valores iguais ou inferiores a 5 (PEDHAZUR; SCHMEKLIN, 1991); o GFI, o CFI, o NFI e o NNFI devem ser superiores a 0,9; o RMSEA deve apresentar valores menores do que 0,08; e o RMSR deve apresentar valor menor do que 0,10 (KLINE, 1998). Frente a esses pressupostos, constatou-se que os índices de ajuste dos construtos iniciais de Valores do Trabalho e Âncoras de Carreira não estavam em conformidade com os valores aceitáveis, indicando a necessidade de ajustes no modelo.

Assim, adotou-se a estratégia de aprimoramento do modelo, na qual o modelo proposto originalmente foi sendo modificado por meio da retirada das relações não significativas e da incorporação de covariâncias entre os erros. Destaca-se que as modificações efetuadas foram fundamentadas nas teorias que sustentaram a construção do modelo, atendendo a premissa de que o processo de modificação das relações estruturais deve buscar consistência teórica (ULLMAN, 2007). Assim, as inclusões de novas relações sugeridas pelo relatório de modificações do pacote estatístico ulilizado $\left(\mathrm{AMOS}^{\mathrm{TM}}\right.$ ) só foram aceitas quando sustentadas por uma argumentação teórica que as justificassem.

Nesta etapa, inicialmente foram incluídas relações entre os erros de variáveis pertencentes ao mesmo construto. Assim, foram incluídas duas relações entre os erros das variáveis do construto Autodeterminação e estimulação (erro da variável "ter um trabalho criativo" com o erro da variável "ter um trabalho inovador"; erro da variável "ter um trabalho que permita expressar meus conhecimentos" com o erro da variável "ter um trabalho que requer originalidade"); uma relação entre as variáveis do construto Segurança (erro da variável "obter estabilidade financeira" com o erro da variável "ganhar dinheiro"); e uma relação entre as variáveis do construto Poder (erro da variável "supervisionar outras pessoas" com o erro da variável "ter prestígio"). As relações justificam-se, pois os erros das variáveis correlacionadas pertencem ao mesmo construto, apresentando interações.

Ainda, visando à melhoria dos índices de ajuste, optou-se por incluir relações entre os erros de variáveis de construtos distintos, mas que apresentavam interações. Foram incluídas relações entre os erros de duas variáveis do construto Gerência geral e duas variáveis do construto Autonomia e Independência (erro da variável "tornar-me um gerente geral é mais atraente para mim do que me tornar um gerente técnico em minha área de especialização" com o erro da variável "sinto-me mais realizado em meu trabalho quando tenho inteira

REAd | Porto Alegre - Edição 79 - N 3 - setembro/dezembro 2014 - p. 625-657 
Taís de Andrade, Kelmara Mendes Vieira, Vania de Fátima Barros Estivalete \& Reisoli Bender Filho

liberdade de definir minhas tarefas, horários e método"; e erro da variável "prefiro deixar meu emprego a aceitar atribuições que me afastem da trajetória de exercer uma função de gerência geral" com o erro da variável "prefiro deixar meu emprego a aceitar atribuições que reduzam minha autonomia e liberdade").

Tais relações justificam-se, pois o construto Gerência geral (associado ao trabalho desafiador e variado, bem como a oportunidades de liderança que permitam a contribuição para a organização) e o construto Autonomia/independência (associado à valorização das experiências profissionais de realização do trabalho cujos ritmos, formas e padrões são autônomos) (COETZEE; SCHREUDE; TLADINYANE, 2007) possuem uma interface. Ainda, tais descrições remetem ao entendimento de que indivíduos que vislumbram a âncora Gerência geral desejam possuir autonomia e independência para realizar suas atividades profissionais, reforçando a existência de relações entre os referidos construtos.

Sob a mesma perspectiva, incluiu-se uma relação entre os erros de uma variável do construto Desafio puro ("sinto-me mais realizado em relação a minha carreira quando resolvo problemas aparentemente insolúveis ou venço em situações adversas") e o erro do construto Criatividade empreendedora, sendo esta justificada pela interação entre os dois construtos, os quais estão associados à abertura à mudança (WILS; WIL; TREMBLAY, 2010). Além disso, o conteúdo da respectiva variável sugere sua associação à âncora Criatividade empreendedora, na medida em que esta se relaciona à superação de obstáculos e desafios, a partir do esforço e da determinação individual.

Optou-se por incluir, também, uma relação entre os erros de uma variável do construto Serviço e dedicação a uma causa e uma variável do construto Desafio puro (erro da variável "sonho em ter uma carreira que dê uma contribuição para a humanidade e a sociedade" com o erro da variável "procuro oportunidades profissionais que desafiem minha capacidade de solucionar problemas"), as quais possuem similaridades em relação ao seu conteúdo. Ao analisar as respectivas variáveis, pode-se inferir que uma carreira cujo seja contribuir com a humanidade e com a sociedade pode estar associada ao desafio da capacidade individual de solucionar problemas.

Por fim, foram adicionadas relações entre os erros dos construtos Desafio Puro e Serviço e dedicação a uma causa e entre os erros dos construtos Desafio Puro e Autonomia/independência. Como destacam Wils, Wils e Tremblay (2010), as âncoras Desafio puro e Autonomia/independência apresentam conteúdos motivacionais semelhantes, associados à abertura à mudança e a situações desafiadoras, as quais também podem associar-

REAd | Porto Alegre - Edição 79 - N 3 - setembro/dezembro 2014 - p. 625-657 
A influência dos Valores Relativos ao Trabalho nas decisões de carreira: um estudo sobre as perspectivas de discentes de instituições de ensino superior

se à âncora Serviço e dedicação a uma causa, que compreende aspectos relacionados à autotranscendência e a soluções de problemas de outras pessoas.

Comparando os resultados dos índices de ajuste iniciais e finais para os construtos de segunda ordem (Valores do Trabalho e Âncoras de Carreira), percebe-se que, em termos de qui-quadrado, há melhora na relação qui-quadrado/graus de liberdade. Os demais índices de ajustamento (GFI, CFI, NFI e NNFI) melhoraram e ficaram acima do limite de 0,9 , indicando um bom ajuste do modelo. O RMR e o RMSEA também apresentaram melhora, ficando abaixo dos limites máximos desejáveis $(0,10$ e 0,08$)$, indicando que os resíduos são adequados. Desse modo, a inserção das covariâncias permitiu melhora substancial nos índices de ajuste finais, como evidenciado na Tabela 2.

Tabela 2 - Resultados dos índices de ajuste dos construtos de $2^{\mathrm{a}}$ ordem

\begin{tabular}{l|c|c|c|c}
\hline & \multicolumn{2}{|c|}{ Valores do Trabalho } & \multicolumn{2}{c}{ Ancoras de Carreira } \\
\hline Índices de Ajuste & Iniciais & Finais & Iniciais & Finais \\
$\chi^{2}$ - Qui-quadrado & 1228,790 & 485,5 & 732,287 & 564,812 \\
& $\mathrm{p}=0,000$ & $\mathrm{p}=0,000$ & $\mathrm{p}=0,000$ & $\mathrm{p}=0,000$ \\
Graus de Liberdade & 177 & 123 & 195 & 171 \\
GFI - Goodness-of-fit & 0,873 & 0,946 & 0,935 & 0,949 \\
CFI - Comparative Fit Index & 0,873 & 0,949 & 0,931 & 0,946 \\
NFI - Normed Fit Index & 0,855 & 0,934 & 0,909 & 0,925 \\
NNFI - Non-Normed Fit Index & 0,849 & 0,937 & 0,919 & 0,934 \\
RMSR- Root Mean Square Residual & 0,048 & 0,040 & 0,109 & 0,090 \\
RMSEA- R.M.S Error of Aproximation & 0,079 & 0,055 & 0,054 & 0,049 \\
\hline
\end{tabular}

Fonte: elaborado pelos autores com base nos resultados da pesquisa

Após o aprimoramento do modelo proposto, este foi constituído por onze construtos de primeira ordem e dois construtos de segunda ordem. Um resumo dos coeficientes padronizados e da significância pode ser visualizado na Tabela 3. 
Taís de Andrade, Kelmara Mendes Vieira, Vania de Fátima Barros Estivalete \& Reisoli Bender Filho

Tabela 3 - Coeficiente padronizado e significância

\begin{tabular}{|c|c|c|c|c|c|c|c|}
\hline $\begin{array}{l}\text { Construto de } \\
1^{\text {a }} \text { ordem }\end{array}$ & Variáveis & Coef. Padr. & $\mathbf{Z}$ & $\begin{array}{l}\text { Construto de } \\
1^{\text {a }} \text { ordem }\end{array}$ & Variáveis & Coef. Padr. & $\mathbf{Z}$ \\
\hline \multirow{6}{*}{$\begin{array}{l}\text { Autodetermin. } \\
\text { e estimulação }\end{array}$} & $\mathrm{a} 22$ & 0,65 & 1 & \multirow{6}{*}{$\begin{array}{c}\text { Autonomia/ } \\
\text { independência }\end{array}$} & b11 & 0,68 & 1 \\
\hline & a31 & 0,68 & 18,80 & & b19 & 0,72 & 17,98 \\
\hline & $\mathrm{a} 34$ & 0,65 & 17,79 & & $\mathrm{~b} 27$ & 0,68 & 17,08 \\
\hline & a35 & 0,69 & 18,46 & & b35 & 0,66 & 15,79 \\
\hline & a36 & 0,75 & 20,23 & & & & \\
\hline & a30 & 0,67 & 18,20 & & & & \\
\hline \multirow{4}{*}{ Segurança } & a6 & 0,51 & 1 & \multirow{4}{*}{$\begin{array}{l}\text { Segurança/ } \\
\text { estabilidade }\end{array}$} & $\mathrm{b} 28$ & 0,71 & 1 \\
\hline & a8 & 0,56 & 15,98 & & b36 & 0,76 & 17,19 \\
\hline & a11 & 0,76 & 16,50 & & b20 & 0,70 & 16,31 \\
\hline & a15 & 0,82 & 16,11 & & & & \\
\hline \multirow{4}{*}{$\begin{array}{l}\text { Universalismo } \\
\text { e benevolência }\end{array}$} & & & & \multirow{4}{*}{ Gerência geral } & b10 & 0,80 & 1 \\
\hline & a18 & 0,74 & & & b18 & 0,80 & 19,19 \\
\hline & $\mathrm{a} 21$ & 0,72 & 17,99 & & b26 & 0,75 & 18,18 \\
\hline & & & & & b34 & 0,61 & 15,24 \\
\hline \multirow{3}{*}{ Realização } & a13 & 0,69 & 1 & \multirow{3}{*}{$\begin{array}{l}\text { Criatividade } \\
\text { empreendedora }\end{array}$} & b5 & 0,79 & 1 \\
\hline & a16 & 0,85 & 22,89 & & b13 & 0,71 & 20,51 \\
\hline & a17 & 0,83 & 21,73 & & b37 & 0,79 & 23,02 \\
\hline \multirow{7}{*}{ Poder } & \multirow{7}{*}{$\begin{array}{l}\text { a19 } \\
\text { a23 } \\
\text { a26 }\end{array}$} & \multirow{7}{*}{$\begin{array}{l}0,72 \\
0,72 \\
0,71\end{array}$} & \multirow{7}{*}{$\begin{array}{c}1 \\
17,40 \\
17,19\end{array}$} & \multirow{3}{*}{$\begin{array}{c}\text { Serviço/ } \\
\text { dedicação a } \\
\text { uma causa }\end{array}$} & b14 & 0,61 & 1 \\
\hline & & & & & $\mathrm{b} 22$ & 0,65 & 15,34 \\
\hline & & & & & b30 & 0,75 & 16,32 \\
\hline & & & & \multirow{4}{*}{ Desafio puro } & b31 & 0,71 & 1 \\
\hline & & & & & b7 & 0,67 & 18,19 \\
\hline & & & & & b15 & 0,67 & 17,28 \\
\hline & & & & & $\mathrm{b} 23$ & 0,65 & 16,65 \\
\hline
\end{tabular}

${ }^{1}$ valor de Z não calculado, pois o parâmetro for arbitrariamente fixado em 1,0; significativo ao nível de 1\%. Fonte: elaborado pelos autores com base nos resultados da pesquisa

Em relação aos fatores dos Valores Relativos ao Trabalho e das Âncoras de Carreira, a perspectiva dos entrevistados pode ser visualizada na Tabela 4, por meio das médias e do desvio padrão de seus fatores. 
A influência dos Valores Relativos ao Trabalho nas decisões de carreira: um estudo sobre as perspectivas de discentes de instituições de ensino superior

Tabela 4 - Média e desvio padrão dos fatores dos Valores Relativos ao Trabalho e das Âncoras de Carreira

\begin{tabular}{l|c|c|l|c|c}
\hline Valores Relativos ao Trabalho & Média & Desvio & Âncoras de Carreira & Média & Desvio \\
\hline Segurança & 4,37 & 0,56 & Segurança/estabilidade & 4,22 & 1,03 \\
Realização & 4,30 & 0,60 & Desafio puro & 4,12 & 1,06 \\
Universalismo e benevolência & 4,04 & 0,55 & Serviço dedicação a uma causa & 3,98 & 1,09 \\
Autodeterminação e estimulação & 3,69 & 0,58 & Criatividade empreendedora & 3,77 & 1,15 \\
Poder & 3,11 & 0,83 & Autonomia/independência & 3,69 & 1,21 \\
& & & Gerência geral & 3,09 & 1,21 \\
\hline
\end{tabular}

Fonte: elaborado pelos autores com base nos resultados da pesquisa

Considerando os Valores Relativos ao Trabalho, percebe-se que, na amostra investigada, as maiores médias foram atribuídas aos valores Segurança $(4,37)$, Realização $(4,30)$ e Universalismo e benevolência (4,04). Como afirmam Ros et al. (1999), os colaboradores que priorizam a segurança buscam estabilidade no trabalho, com o objetivo de possuir uma renda necessária à manutenção da ordem de suas vidas, sendo este valor associado à dimensão Conservação. O valor Realização evidencia a busca da satisfação pessoal, por meio da utilização de competências reconhecidas socialmente, estando associado à dimensão Autopromoção (PORTO; PILATI, 2010). Já o valor Universalismo e benevolência está associado à prioridade aos interesses e ao bem-estar da coletividade (SCHWARTZ, 2005), incluindo a valorização da cooperação e das interações sociais.

Esses resultados evidenciam que os indivíduos priorizam valores com conteúdos motivacionais distintos e até mesmo antagônicos, associados tanto aos interesses individuais, relacionados à autopromoção (Realização), quanto aos interesses coletivos, relacionados à autotranscendência (Universalismo e benevolência). Tais constatações podem estar associadas à heterogeneidade da amostra, composta de 958 indivíduos, os quais pertencem a oito cursos de graduação, possuindo experiências profissionais diversas e tendo perspectivas distintas acerca da valorização de aspectos pertinentes ao trabalho.

Ao analisar as Âncoras de Carreira, as maiores médias foram atribuídas às âncoras Segurança/estabilidade $(4,22)$ e Desafio puro $(4,12)$. A âncora Segurança/estabilidade, associada ao conservadorismo (WILS; WILS; TREMBLAY, 2010), denota a preocupação dos indivíduos com oportunidades de emprego estável, a busca de um emprego que ofereça segurança financeira e que permita equilibrar e integrar as necessidades pessoais, familiares e profissionais (COETZEE; SCHREUDER, 2008). Por outro lado, a âncora Desafio puro 
Taís de Andrade, Kelmara Mendes Vieira, Vania de Fátima Barros Estivalete \& Reisoli Bender Filho

congrega a competição e as experiências profissionais desafiadoras, bem como a valorização de recompensas obtidas por mérito próprio (SCHEIN, 1996), estando associada à perspectiva de abertura à mudança.

As Âncoras de Carreira predominantes demonstram, também, preferências distintas entre os discentes, o que pode estar relacionado aos interesses e às experiências profissionais diversas vivenciadas pelos indivíduos que compuseram a amostra deste estudo. Toit e Coetzee (2012), ao investigarem uma amostra composta por cientistas e engenheiros, também identificaram âncoras com conteúdos distintos (Estilo de vida, Desafio puro e Serviço e dedicação a uma causa), sendo as diferenças constatadas associadas às variáveis de perfil, como gênero e faixa etária.

Após a aplicação da Análise Fatorial Confirmatória para a validação dos construtos de primeira e segunda ordem e da análise descritiva, buscou-se avaliar o modelo integrado que agrega o modelo de mensuração e o modelo estrutural.

\subsection{Modelo Integrado: identificando a influência dos Valores Relativos ao Trabalho sobre as Âncoras de Carreira}

Visando identificar a influência do construto Valores do Trabalho sobre o construto Âncoras de Carreira, da mesma forma que para a AFC, inicialmente trabalhou-se com a ideia de aprimoramento do modelo, com base nas sugestões do software AMOSTM. Assim, foram incluídas correlações entre os erros dos construtos Segurança (Valores do Trabalho) e Segurança/estabilidade (Âncoras de Carreira), entre os erros dos construtos Universalismo e benevolência (Valores do Trabalho) e Serviço e dedicação a uma causa (Âncoras de Carreira) e entre os erros dos construtos Poder (Valores do Trabalho) e Gerência geral (Âncoras de Carreira).

Ao analisar as relações entre os erros dos construtos dos Valores do Trabalho e das Âncoras de Carreira, percebe-se que essas possuem um respaldo teórico. Considerando o Modelo Circular de Âncoras de Carreira proposto por Wils, Wils e Tremblay (2010), o qual evidencia a correspondência entre os valores e as âncoras, constatou-se que tanto o valor Segurança quanto a âncora Segurança/estabilidade pertencem à dimensão Conservação, associada à busca pela manutenção da harmonia e do equilíbrio. Já o valor Universalismo e benevolência e a âncora Serviço e dedicação a uma causa pertencem à dimensão Autotranscendência, relacionada à preocupação com os interesses coletivos; e o valor Poder e a âncora Gerência geral pertencem à dimensão Autopromoção, associada à busca dos interesses individuais e à influência sobre os demais (SCHWARTZ, 2005; SCHWARTZ,

REAd | Porto Alegre - Edição 79 - N 3 - setembro/dezembro 2014 - p. 625-657 
A influência dos Valores Relativos ao Trabalho nas decisões de carreira: um estudo sobre as perspectivas de discentes de instituições de ensino superior

1992; WILS; WILS; TREMBLAY, 2010), justificando a inclusão das referidas correlações entre os erros.

Após esse procedimento, o modelo final aprimorado apresentou os índices de ajuste observados na Tabela 5.

Tabela 5 - Índices de ajuste do modelo final

\begin{tabular}{l|c}
\hline \multicolumn{1}{c|}{ Índice } & Valor \\
\hline$\chi^{2}$ - Qui-quadrado & 1801,642 \\
Graus de Liberdade & $\mathrm{P}=0,000$ \\
GFI - Goodness of Fit & 667 \\
CFI - Comparative Fit Index & 0,910 \\
NFI - Normed Fit Index & 0,927 \\
NNFI - Non Normed Fit Index & 0,890 \\
RMSR - Root Mean Square Residual & 0,919 \\
RMSEA - Root Mean Squared Error of Aproximation & 0,091 \\
\hline
\end{tabular}

Fonte: elaborado pelos autores com base nos resultados da pesquisa

Como pode ser observado, os índices de ajuste mostraram-se adequados aos valores considerados satisfatórios, exceto para o índice de ajuste NFI. No entanto, como os demais índices de ajuste foram adequados e o NFI apresentou valor próximo a 0,9, pode-se considerar a aceitação do modelo estrutural. Situações semelhantes foram constatadas em outros modelos estruturais de estudos na área de Administração, que também foram tidos como adequados (FREITAS; MARQUES, 2010; ROWE, BASTOS; PINHO, 2011).

Analisando o modelo final (Figura 4), considerando os pesos de regressão padronizados (standardized regression weights), pode-se constatar que os construtos de primeira ordem Universalismo e benevolência $(0,74)$, Poder $(0,72)$ e Autodeterminação e estimulação $(0,69)$ são os mais relacionados com o construto Valores do Trabalho, bem como os construtos de primeira ordem Autonomia/independência $(0,87)$, Desafio puro $(0,77)$, Gerência geral $(0,71)$ e Criatividade empreendedora $(0,70)$ são os mais relacionados com o construto Âncoras de Carreira. Quanto à significância, verifica-se que o peso da regressão para todos os construtos é significativamente diferente de zero, ao nível de $1 \%$ de significância.

Esses resultados sugerem que o construto de segunda ordem Valores do Trabalho é formado, principalmente, pelos valores Universalismo e benevolência, Poder e Autodeterminação e Estimulação, os quais estão associados a três das quatro dimensões dos 
Taís de Andrade, Kelmara Mendes Vieira, Vania de Fátima Barros Estivalete \& Reisoli Bender Filho

Valores do Trabalho defendidas por Porto e Tamayo (2003) e Porto e Pilati (2010): Realização no Trabalho, Relações Sociais e Prestígio. Tais achados confirmam o caráter multidimensional dos Valores do Trabalho, os quais congregam interesses individuais múltiplos.

Ao considerar o construto Âncoras de Carreira, constatou-se que esse foi formado principalmente pelos construtos de primeira ordem Autonomia/independência, Desafio puro, Gerência geral e Criatividade empreendedora, sugerindo a existência da diversidade de interesses associados à carreira profissional que contribuem para explicar o fenômeno.

O diagrama do modelo final é apresentado na Figura 4. Ressalta-se que, nesta Figura, exposta a seguir, foram omitidos os erros das variáveis e dos construtos e as respectivas correlações entre os erros.

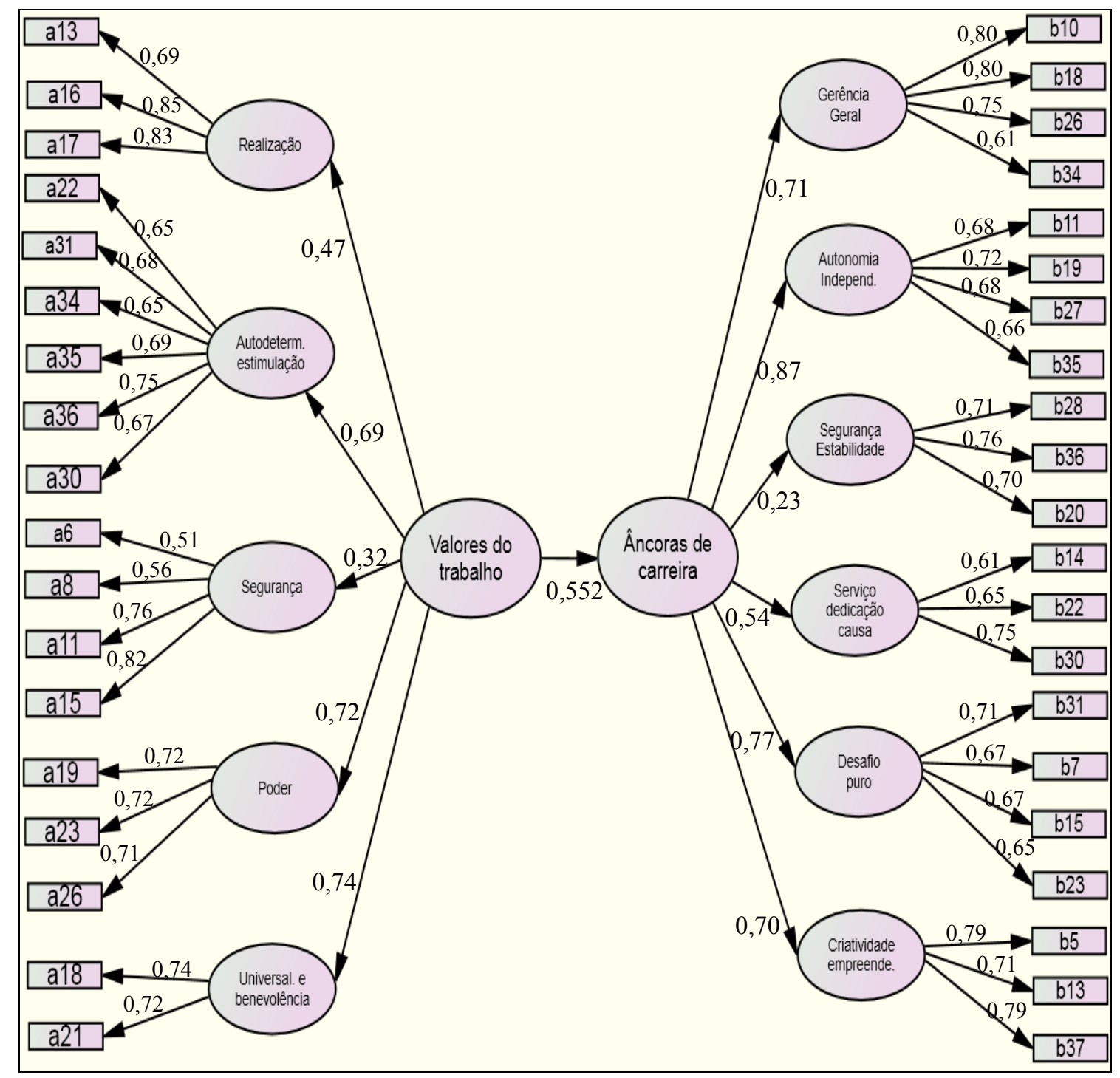

Figura 4 - Diagrama do modelo final

Fonte: elaborado pelos autores com base nos resultados da pesquisa

REAd | Porto Alegre - Edição 79 - N 3 - setembro/dezembro 2014 - p. 625-657 
A influência dos Valores Relativos ao Trabalho nas decisões de carreira: um estudo sobre as perspectivas de discentes de instituições de ensino superior

Ainda em relação ao modelo final, analisou-se o $\mathrm{R}^{2}$ (obtido por meio do quadrado do coeficiente de correlação) para verificar a influência dos Valores Relativos ao Trabalho sobre as Âncoras de Carreira. Os resultados do $\mathrm{R}^{2}$ indicam que o construto Valores do Trabalho explica $30,5 \%\left(0,552^{2}\right)$ da variância do construto Âncoras de Carreira. Nesse sentido, percebe-se que o coeficiente de determinação demonstrou que os Valores do Trabalho destacados no modelo contribuem significativamente para explicar as Âncoras de Carreira, pois, como afirmam Hair et al. (2009), quanto maior o valor de $\mathrm{R}^{2}$, melhor a previsão da variável dependente.

Tal constatação vai ao encontro das perspectivas defendidas por Toit e Coetzee (2012) e Wils, Wils e Tremblay (2010) de que os valores exercem influência sobre as decisões de carreira e as escolhas profissionais. Além disso, o modelo proposto amplia as considerações acerca dos Valores do Trabalho e das Âncoras de Carreira, destacando a existência de interações entre esses construtos e sinalizando a pertinência de investigações conjuntas sobre os temas, pois permite o melhor entendimento acerca das demandas individuais e de sua interface com as perspectivas sobre carreira.

A análise proposta neste estudo pode oferecer uma direção e um suporte teórico para ampliar as considerações sobre os antecedentes das Âncoras de Carreira, já que o modelo proposto pode contribuir para melhor compreender o comportamento dos indivíduos frente às decisões profissionais. Os resultados obtidos a partir da perspectiva dos discentes de IES permitem constatar que as decisões acerca de sua carreira profissional não estão somente embasadas nas preferências individuais, mas também no valor atribuído ao trabalho.

Do ponto de vista de sua aplicação, o presente estudo forneceu um pertinente ponto de partida para a reflexão em busca de novas formas de compreender os sentidos atribuídos ao trabalho e os motivos que levam os indivíduos a decidirem sobre suas carreiras profissionais. Diante de um cenário caracterizado por intensas transformações que afetaram o mundo do trabalho, os temas abordados neste estudo assumem grande relevância para que as organizações e os profissionais da área de gestão invistam em aprofundar o conhecimento acerca das aspirações e dos valores atribuídos ao trabalho por parte dos indivíduos, pois estes irão impactar em suas perspectivas de carreira.

\section{CONSIDERAÇÕES FINAIS}

Este trabalho procurou analisar a influência dos Valores Relativos ao Trabalho sobre as Âncoras de Carreira, a partir da perspectiva de discentes de IES, valendo-se do pressuposto de que os valores antecedem as escolhas e decisões de carreira individuais (TOIT; COETZEE,

REAd | Porto Alegre - Edição 79 - N 3 - setembro/dezembro 2014 - p. 625-657 
Taís de Andrade, Kelmara Mendes Vieira, Vania de Fátima Barros Estivalete \& Reisoli Bender Filho

2012; WILS; WILS; TREMBLAY, 2010). Considerando que as análises conjuntas entre valores e decisões de carreira são escassas no contexto internacional e, principalmente, nacional, optou-se por propor um modelo que mensurasse tal relação de influência.

A realização da AFC para a validação dos construtos, a avaliação da confiabilidade e os índices de ajuste evidenciaram a necessidade de aprimoramento do modelo, realizado por meio da inclusão de covariâncias entre os erros, bem como da exclusão de algumas variáveis. Após essas etapas, o modelo final apresentou índices de ajuste satisfatórios, contendo onze construtos de primeira ordem e dois construtos de segunda ordem. Esses resultados demonstraram que a EVT-R, proposta por Porto e Pilati (2010) e o Inventário de Âncoras de Carreira, desenvolvido por Schein $(1993 ; 1996)$, não apresentaram um comportamento estável na amostra investigada, sendo necessário a exclusão de três fatores dos referidos instrumentos.

Ressalta-se, ainda, que a análise do modelo estrutural permitiu identificar que o construto Valores do Trabalho explica 30,5\% $\left(\mathrm{R}^{2}\right)$ da variância do construto Âncoras de Carreira. De maneira geral, o presente trabalho evidenciou a influência dos Valores Relativos ao Trabalho sobre as Âncoras de Carreira, pressuposto esse com poucas evidências empíricas até então. Em termos teóricos, esse achado sustenta a importância das demandas internas, representadas pelos valores que os indivíduos atribuem ao trabalho, sobre as escolhas profissionais. Tais resultados sugerem a relevância de se considerar os valores como variáveis promissoras para a compreensão de perspectivas subjetivas em relação às decisões de carreira, o que pode contribuir para o seu planejamento, considerando tanto a dimensão individual quanto a organizacional.

No entanto, como qualquer trabalho, a presente pesquisa apresenta alguns limites que devem ser considerados na avaliação do alcance dos seus resultados. Assim, cabe destacar que o referido modelo constatou a relação de influência entre os construtos de segunda ordem, não sendo identificadas especificamente as interações entre os Valores do Trabalho (Realização, Autodeterminação e estimulação, Segurança, Poder e Universalismo e benevolência) e as Âncoras de Carreira (Gerência geral, Autonomia/independência, Segurança, Estabilidade, Serviço e dedicação a uma causa, Desafio puro e Criatividade empreendedora), representados pelos construtos de primeira ordem. Além disso, a existência de correlação entre os erros de construtos dos Valores do Trabalho e das Âncoras de Carreira sugerem a necessidade de investigar com mais especificidade a interação entre esses construtos. 
A influência dos Valores Relativos ao Trabalho nas decisões de carreira: um estudo sobre as perspectivas de discentes de instituições de ensino superior

Ainda, mesmo apresentando valores significativos, o $\mathrm{R}^{2}$ demonstrou que existem outras variáveis independentes, não analisadas neste estudo, que também influenciam as Âncoras de Carreira. Portanto, abre-se espaço para pesquisas futuras que visem ampliar o modelo desenvolvido neste estudo.

Sugere-se, assim, que modelos explicativos mais amplos, que considerem outras variáveis independentes, além dos Valores Relativos ao Trabalho, sejam desenvolvidos e testados em estudos posteriores. Considerando a relevância dessa temática no contexto laboral e a necessidade de melhor compreensão acerca dos motivos que levam os indivíduos a trabalhar e a tomar decisões sobre suas carreiras, recomenda-se, também, a realização de pesquisas dessa natureza em outros segmentos, congregando aspectos associados à realização e satisfação no trabalho e permitindo, assim, uma análise mais abrangente sobre esses temas.

\section{REFERÊNCIAS}

ARTHUR, M.B. Examining contemporary careers: a call for interdisciplinary inquiry. Human Relations, v.61, n. 2, p.163-186, 2008.

BAKER, M. J. Selecting a research methodology. The Marketing Review, v.1, n.3, p. 373397, 2001.

BAUMGARTNER, H.; HOMBURG, C. Applications of structural equation modeling in marketing and consumer research: a review. International Journal of Research in Marketing, v.13, n.2, p.139-161, 1996.

BENDASSOLLI, O.F. Recomposição da relação sujeito- trabalho nos modelos emergentes de carreira. Revista de Administração de Empresas, v. 49, n.4, p. 387-400, 2009.

BLANCH, J. M. Trabajar en la modernidad industrial. In: BLANCH, J.M. (Org.), Teoría de las relaciones laborales: fundamentos. Barcelona: UOC, 2003.

CAMPOS, B. A. Estrutura de valores relativos ao trabalho. In: TEIXEIRA, M. L. M. (Ed.), Valores humanos e gestão: novas perspectivas. São Paulo, Serviço Nacional de Aprendizagem Comercial, 2008, p. 389-408.

CHANG, R.D.; WUNN, K.T.; TSENG, Y.C. A study of the relationships between career orientation, achievement motivation, job satisfaction, and intention to stay for auditors. Journal of Business and Economics Research, v.1, n.4, p.117-128, 2011.

CHIN, W.W. Issues and opinion on structural equation modeling. MIS Quarterly, v. 22, n.1, p. 7-16, 1998. 
Taís de Andrade, Kelmara Mendes Vieira, Vania de Fátima Barros Estivalete \& Reisoli Bender Filho

CHURCHILL, G. A. Jr. A paradigm of developing better measures of marketing constructs. Journal of Marketing Research, v.16, n.1, p.64-73, 1979.

COETZEE, M.; SCHREUDER, D. The relation between career anchors, emotional intelligence and employability satisfaction among workers in the service industry. Southern African Business Review, v. 15, n. 3, p. 76-97, 2011.

COETZEE, M.; SCHREUDER, D.; TLADINYANE, R.; Organisational commitment and its relation to career anchors. Southern African Business Review, v.11, n. 1, p. 65-86, 2007.

COUTINHO, M.C. Sentidos do trabalho contemporâneo: as trajetórias identitárias como estratégia de investigação. Cadernos de Psicologia Social do Trabalho, v. 12, n. 2, p. 189$202,2009$.

DANZIGER, N.; RACHMAN-MOORE, D.; VALENCY, R. The construct validity of Schein's career anchors orientation inventory. Career Development International, v. 13, n. 1, p. 7-19, 2008.

DAWIS, R.V.; LOFQUIST, L.H. A psychological theory of work adjustment. Minnesota, University of Minnesota Press, 2004.

DECI, E.L.; RYAN, R.M. Human autonomy: the basis of true self -esteem. In: KERNIS, M. (Ed). Efficacy, agency and self-esteem. New York: Plenum Publishing CO, 1995, p. 31-49.

DECI, E.L.; RYAN, R.M. The "what" and "why" of goal pursuits: human needs and the self determination of behavior. Psychological Inquiry, v. 11, n.1, p. 227-268, 2000.

ELIZUR, D.; SAGIE, A. Facets of personal values: A structural analysis of life and work values. Applied Psychology: An International Review, v.48, n.1, p.73-87, 1999.

FARO, E.S.C.; AMORIM, M.C.S.; TREVISAN, L. JUNQUEIRA, L.A.P. Âncoras de carreira e transformações no modelo de administração: estudo de caso do Tribunal de Contas da União (TCU). Cadernos EBAPE.BR, v.8, n.4, p. 710-733, 2010.

FREITAS, M.N.C.; MARQUES, A.L. Formas de ver as pessoas com deficiência: um estudo empírico do construto de concepções de deficiência em situações de trabalho. Revista de Administração Mackenzie, v.11, n.3, p. 100-129, 2010.

GARVER, M.S.; MENTZER, J.T. Logistics research methods: employing structural equation modeling to test for construct validity. Journal of Business Logistics, v. 20, n.1, p.33-57, 1999.

GUNZ, H.; PEIPERL, M. Handbook of career studies. Los Angeles, CA: SAGE, 2007. 
A influência dos Valores Relativos ao Trabalho nas decisões de carreira: um estudo sobre as perspectivas de discentes de instituições de ensino superior

HAIR, J. F. ;BLACK, W.C. ; BABIN, B.J. ; ANDERSON, R. A. ; TATHAM, R. L. Análise multivariada de dados. 6. ed. Porto Alegre: Bookman, 2009.

HAIR, J.F. MONEY, A.H.; BABIN, B.; SAMOUEL, P. Fundamentos de métodos de pesquisa em administração. Porto Alegre: Bookman, 2005.

HARPAZ, I. Meaning of working profiles of various occupational groups. Journal of Vocational Behavior, v. 26, n.1, p. 25-40, 1985.

HIRSCHI, A. Callings in career: a typological approach to essential and optional components. Journal of Vocational Behavior, v.79, n.3, p. 60-72, 2011.

HOLLAND, J. L. Making vocational choices: a theory of careers. Englewood Cliffs, NJ: Prentice Hall , 1973.

JIN, J.; ROUNDS, J. Stability and change in work values: a meta-analysis of longitudinal studies. Journal of Vocational Behavior, v. 80, n.2, p. 326-339, 2012.

JUNG, C.G. The portable Jung. New York: The Viking Press, 1971.

KLINE, R. B. Principles and practice of structural equation modeling. New York: The Guilford Press, 1998.

LEUTY, M.E.; HANSEN, J.I.C. Evidence of construct validity for work values. Journal of Vocational Behavior, v.79, n, 2, p. 379-390, 2011.

LUMLEY, E.J. Exploring the relationship between career anchors, job satisfaction and organizational commitment. 233 p. Master of Commerce - University of South Africa, Pretoria, 2009.

LYONS, S. T.; HIGGINS; C. A.; DUXBURY, L. Work values: development of a new threedimensional structure based on confirmatory smallest space analysis. Journal of Organizational Behavior, v. 31, n.7, p. 969-1002, 2010.

PEDHARZUR, E. J., SCHMELKIN, L. P. Measurement, design, and analysis: an integrated approach. Mahwah, N.J.: Lawrence Erlbaum, 1991.

PILATI, R.; LAROS, J.A. Modelos de equações estruturais em psicologia: conceitos e aplicações. Psicologia: Teoria e Pesquisa, v. 23 n. 2, p. 205-216, 2007.

PORTO, J.B.; PILATI, R. Escala revisada de valores relativos ao trabalho- EVT-R. Psicologia: Reflexão e Crítica, v. 23, n.1, p. 73-82, 2010.

PORTO, J.; TAMAYO, A. Desenvolvimento e validação da escala de valores do trabalho EVT. Psicologia: Teoria e Pesquisa, v. 19, n. 1, p. 145-152, 2003.

REAd | Porto Alegre - Edição 79 - N 3 - setembro/dezembro 2014 - p. 625-657 
Taís de Andrade, Kelmara Mendes Vieira, Vania de Fátima Barros Estivalete \& Reisoli Bender Filho

PORTO, J. B.; TAMAYO, A. Estrutura dos valores pessoais: a relação entre valores gerais e laborais. Psicologia: Teoria e Pesquisa, v. 23, n.1, p. 63-70, 2007.

ROS, M. GRAD, H. O significado do valor trabalho relacionado à experiência ocupacional: uma comparação entre professores primários e estudantes do CAP. In: TAMAYO, A.; PORTO, J. B. (Orgs.), Valores e comportamento nas organizações. Petrópolis: Vozes, 2005, p. 251-279.

ROS, M.; SCHWARTZ, S.H.; SURKISS, S. Basic individual values, work values and the menaning of work. Applied Psychology: An International Review, v.48, n. 2, p. 49-71, 1999.

ROWE, D.E.O.; BASTOS, A.V.B. Vínculos com a carreira e a produção acadêmica: comparando docentes de IES públicas e privadas. Revista de Administração Contemporânea, v. 14, n.6, p. 1011-1030, 2010.

ROWE, D. E.O.; BASTOS, A.V.B.; PINHO, A.P.M. Comprometimento e entrincheiramento na carreira: um estudo de suas influências no esforço instrucional do docente do ensino superior. Revista de Administração Contemporânea, v. 15, n. 6, p. 973-992, 2011.

SANTOS, M.P. O papel do ensino superior na proposta de uma nova educação inclusiva. Revista Movimento, v.1, n.7, p. 78-91, 2003.

SCHEIN, E.H. Career anchors: discovering your real values. Revised edition. San Diego: Pfeiffer e Company, 1993.

SCHEIN, E. H. Career dynamics. Reading, MA: Addison-Wesley, 1978.

SCHEIN, E. H. Identidade profissional: como ajustar suas inclinações e suas opções de trabalho. Tradução de Margarida D. Black. São Paulo: Nobel, 1996.

SCHUMACKER, R. E., LOMAX, R. G. A beginner's guide to structural equation modeling. New Jersey, Lawrence Erlbaum, 1996.

SCHWARTZ, S. H. Valores humanos básicos: seu contexto e estrutura intercultural. In: TAMAYO, A.; PORTO, J. B. (Orgs.) Valores e comportamento nas organizações. Petrópolis: Vozes, 2005, p. 21-55.

SCHWARTZ, S. H. Universals in the content and structure of values: theory and empirical tests in 20 countries. In: ZANNA, M. (Ed.).Advances in experimental social psychology. New York: Academic Press, 1992, p. 1-65.

SCHWARTZ, S. H.; BILSKY, W. Toward a universal psychological structure of human values. Journal of Personality and Social Psychology. v. 52, n. 3, p. 550-562, 1987. 
A influência dos Valores Relativos ao Trabalho nas decisões de carreira: um estudo sobre as perspectivas de discentes de instituições de ensino superior

SOLDANO, S.M. Integrating work and basic values into the spherical model of interests. Journal of Vocational Behavior, v.78, n.1, p. 1-10, 2011, 2011.

SUPER, D.; BOHN, M. Psicologia Ocupacional. São Paulo: Atlas, 1980.

THOMPSON, B. Ten commandments of structural equation modeling. In: GRIMM. L. G.; YARNOLD, P. R. (Orgs.). Reading and understanding more multivariate statistics. Washington: American Psychological Association, 2002.

TOIT, D.M.; COETZEE, M. Archetypal values of science and engineering staff in relation to their career orientations. Journal of Industrial Psychology, v.24, n.1, p. 1-14, 2012.

ULLMAN, J. B. Structural equation modeling. In: TABACHNICK, B. G.; FIDELL, L. S. Fidell (Orgs.). Using multivariate statistics. 5 ed. Boston: Pearson Education, 2007.

VAN DAM, K. Antecedents and consequences of employability orientation. European Journal of Work and Organizational Psycology, v.13, n.1, p.29-51, 2004.

WILS, L.; WILS, T.; TREMBLAY, M. Toward a career anchor structure: an empirical investigation of engineers. Industrial Relations, v.65, n.2, p. 236-256, 2010.

\section{APÊNDICE A - Fatores e variáveis dos Valores do Trabalho e Âncoras de Carreira}

Tabela 6 - Fatores e variáveis dos Valores do Trabalho e Âncoras de Carreira

\begin{tabular}{|c|c|}
\hline \multicolumn{2}{|r|}{$\begin{array}{ll}\text { Valores do trabalho } \\
\end{array}$} \\
\hline Realização & $\begin{array}{l}\text { a13. Ser admirado pelo meu trabalho } \\
\text { a16. Ser reconhecido pelo resultado satisfatório do meu trabalho } \\
\text { a17. Ser respeitado pelas minhas competências no trabalho }\end{array}$ \\
\hline $\begin{array}{l}\text { Autodeter. e } \\
\text { estimulação }\end{array}$ & $\begin{array}{l}\text { a22. Ter desafios constantes } \\
\text { a31. Ter um trabalho inovador } \\
\text { a34. Ter um trabalho que me permita conhecer pessoas novas } \\
\text { a35. Ter um trabalho que me permita expressar meus conhecimentos } \\
\text { a36. Ter um trabalho que requer originalidade } \\
\text { a30. Ter um trabalho criativo }\end{array}$ \\
\hline Segurança & $\begin{array}{l}\text { a6. Obter estabilidade financeira } \\
\text { a8. Ganhar dinheiro } \\
\text { a11. Poder me sustentar financeiramente } \\
\text { a15. Ser independente financeiramente }\end{array}$ \\
\hline Poder & $\begin{array}{l}\text { a19. Supervisionar outras pessoas } \\
\text { a23. Ter fama } \\
\text { a26. Ter prestígio }\end{array}$ \\
\hline $\begin{array}{l}\text { Universalismo } \\
\text { e } \\
\text { benevolência }\end{array}$ & $\begin{array}{l}\text { a18. Ser útil para a sociedade } \\
\text { a21. Ter compromisso social }\end{array}$ \\
\hline \multicolumn{2}{|r|}{ Âncoras de carreira } \\
\hline Gerência geral & $\begin{array}{l}\text { b10. Sonho em dirigir uma empresa complexa e tomar decisões que afetem muitas } \\
\text { pessoas } \\
\text { b18. Somente vou achar que minha carreira é um sucesso se ocupar o cargo de gerente } \\
\text { geral } \\
\text { b26. Tornar-me um gerente geral é mais atraente para mim do que me tornar um gerente } \\
\text { técnico em minha área de especialização }\end{array}$ \\
\hline
\end{tabular}

REAd | Porto Alegre - Edição 79 - N 3 - setembro/dezembro 2014 - p. 625-657 
Taís de Andrade, Kelmara Mendes Vieira, Vania de Fátima Barros Estivalete \& Reisoli Bender Filho

\begin{tabular}{|c|c|}
\hline & $\begin{array}{l}\text { b34. Prefiro deixar meu emprego a aceitar atribuições que me afastem da trajetória de } \\
\text { exercer uma função de gerência geral }\end{array}$ \\
\hline $\begin{array}{l}\text { Autonomia e } \\
\text { independência }\end{array}$ & $\begin{array}{l}\text { b11. Sinto-me mais realizado em meu trabalho quando tenho inteira liberdade de definir } \\
\text { minhas tarefas, horários e métodos } \\
\text { b19. Somente vou achar que minha carreira é um sucesso se conseguir autonomia e } \\
\text { liberdade } \\
\text { b27. Considero mais importante a oportunidade de realizar o trabalho a meu modo, livre } \\
\text { de regras e pressões do que ter segurança. } \\
\text { b35. Prefiro sair de meu emprego a aceitar atribuições que reduzam a minha autonomia }\end{array}$ \\
\hline $\begin{array}{c}\text { Segurança } \\
\text { estabilidade }\end{array}$ & $\begin{array}{l}\text { b25. Prefiro deixar meu emprego a aceitar uma tarefa de rodízio que me afaste da minha } \\
\text { área de especialidade } \\
\text { b36. Sonho em seguir uma carreira que me permita sentir segurança e assegure } \\
\text { estabilidade } \\
\text { b20. Procuro trabalhos em empresas que me deem sensação de segurança e estabilidade }\end{array}$ \\
\hline $\begin{array}{c}\text { Serviço } \\
\text { dedicação a } \\
\text { uma causa }\end{array}$ & $\begin{array}{l}\text { b14. Sinto-me mais realizado em relação à minha carreira quando coloco minha } \\
\text { capacidade a serviço de meus semelhantes } \\
\text { b22. Acho mais importante utilizar minhas aptidões para fazer deste mundo um lugar } \\
\text { melhor para se viver e trabalhar do que alcançar uma posição gerencial de alto nível } \\
\text { b30. Sonho em ter uma carreira que dê uma contribuição para a humanidade e a } \\
\text { sociedade }\end{array}$ \\
\hline Desafio puro & $\begin{array}{l}\text { b31. Procuro oportunidades profissionais que desafiem minha capacidade de solucionar } \\
\text { problemas } \\
\text { b7. Sonho com uma carreira que me possibilite solucionar problemas ou vencer em } \\
\text { situações desafiadoras } \\
\text { b15. Somente considerarei minha carreira um sucesso se superar situações difíceis } \\
\text { b23. Sinto-me mais realizado em relação à minha carreira quando resolvo problemas } \\
\text { aparentemente insolúveis ou venço em situações muito adversas }\end{array}$ \\
\hline $\begin{array}{l}\text { Criatividade } \\
\text { empreendedora }\end{array}$ & $\begin{array}{l}\text { b5. Estou sempre à procura de ideias que me permitam dar início a um empreendimento } \\
\text { próprio } \\
\text { b13. Acho mais importante ter meu próprio negócio do que atingir uma alta posição } \\
\text { gerencial como empregado } \\
\text { b37. Sonho em iniciar e fazer crescer meu próprio empreendimento }\end{array}$ \\
\hline
\end{tabular}

Fonte: elaborado a partir de Porto e Pilati (2010) e Schein (1993; 1996) 